\title{
Prognostic Value of Blood Urea Nitrogen/Creatinine Ratio for Septic Shock: An Analysis of the MIMIC-III Clinical Database
}

\author{
Didi Han $\mathbb{D}^{1,2}$ Luming Zhang $\mathbb{D}^{3},{ }^{3}$ Shuai Zheng $\mathbb{D}^{1,4}$ Fengshuo Xu $\mathbb{D},{ }^{1,2}$ Chengzhuo Li $\mathbb{D},,^{1,2}$ \\ Rui Yang $\mathbb{D}^{1,2}$ Wen Ma $\mathbb{D}^{2},{ }^{2}$ Haiyan Yin $\mathbb{D}^{3},{ }^{3}$ and Jun Lyu $\mathbb{D}^{1,2}$ \\ ${ }^{1}$ Department of Clinical Research, The First Affiliated Hospital of Jinan University, Guangdong Province 510630, China \\ ${ }^{2}$ School of Public Health, Xi'an Jiaotong University Health Science Center, Shaanxi Province 710061, China \\ ${ }^{3}$ Intensive Care Unit, The First Affiliated Hospital of Jinan University, Guangzhou 510630, China \\ ${ }^{4}$ School of Public Health, Shaanxi University of Chinese Medicine, Xianyang, Shaanxi, China
}

Correspondence should be addressed to Haiyan Yin; yinhaiyan1867@126.com and Jun Lyu; lyujun2020@jnu.edu.cn

Received 17 January 2021; Revised 20 March 2021; Accepted 7 May 2021; Published 22 May 2021

Academic Editor: Despina Deligianni

Copyright $\odot 2021$ Didi Han et al. This is an open access article distributed under the Creative Commons Attribution License, which permits unrestricted use, distribution, and reproduction in any medium, provided the original work is properly cited.

Background. Research has previously been done into the risk factors for mortality in septic shock patients. However, there has been no epidemiological study investigating the effect of the blood urea nitrogen/creatinine ratio (BCR) on the prognosis of critically ill septic shock patients. This study is aimed at determining the relationship between BCR and all-cause mortality in adult septic shock patients. Methods. Data were extracted from the MIMIC-III database. The clinical endpoints were 28-, 90-, and 365-day all-cause mortality rates in critically ill septic shock patients. Cox proportional hazards models and subgroup analyses were used to analyze the relationship between BCR quartiles and all-cause mortality in septic shock patients. Receiver operator characteristic (ROC) curves and areas under the ROC curves (AUCs) were calculated to evaluate how accurately BCR predicts the mortality of septic shock patients. Results. Among the 2484 septic shock patients extracted from the database, 619, 563, 677, and 625 fell into the first $(<14.4 \mathrm{mg} / \mathrm{dL})$, second $(\geq 14.4 \mathrm{mg} / \mathrm{dL}$ and $<20.0 \mathrm{mg} / \mathrm{dL})$, third $(\geq 20.0 \mathrm{mg} / \mathrm{dL}$ and $<27.3 \mathrm{mg} / \mathrm{dL})$, and fourth $(\geq 27.3 \mathrm{mg} / \mathrm{dL})$ quartiles of BCR, respectively. Male and white patients accounted for 53.8\% (1336 patients) and 74.8\% (1857 patients) of the population, respectively. The mean age of the population was $67.7 \pm 15.8$ years. An inverse M-shaped relationship between BCR and mortality in septic shock patients was identified, with a value of $\geq 27.3 \mathrm{mg} / \mathrm{dL}$ providing the highest risk $(\mathrm{HR}=1.596,95 \%$ CI: $1.396-1.824, P<0.001)$. In the Cox regression model adjusted for different confounding variables, BCR values in the fourth quartiles were significantly associated with increased mortality, using the first quartiles as a reference. The areas under the ROC curves (AUCs) for BCR plus the Sequential Organ Failure Assessment (SOFA) score and BCR plus Acute Physiology Score III (APSIII) were 0.694 (95\% CI: 0.673-0.716) and 0.724 (95\% CI: 0.703-0.744), respectively. Conclusion. An inverse M-shaped curve was determined between BCR and the mortality of septic shock patients. BCR was identified as a readily available and independent prognostic biomarker for septic shock patients, and higher BCRs were associated with increased mortality in these patients.

\section{Background}

Sepsis is a syndrome of physiological, biochemical, and pathological abnormalities caused by infection [1]. Abnormal circulation and metabolism caused by septic shock can increase the mortality of intensive care unit (ICU) patients $[2,3]$. The mortality rates of sepsis and septic shock have generally decreased, whereas the incidence rates have increased $[4,5]$. Previous studies have indicated that severe sepsis and septic shock might cause $20-30 \%$ of all mortality and $30-50 \%$ of hospital mortality $[6,7]$.

Septic shock is currently defined as sepsis with hypotension, which requires vasopressor therapy to maintain a mean arterial pressure of $65 \mathrm{mmHg}$ or higher. Despite adequate fluid resuscitation, serum lactic acid remains higher than $2 \mathrm{mmol} / \mathrm{L}$ [8]. The identification of risk factors that affect the prognosis of critically ill patients is helpful to guide medical workers and patients to take early intervention measures 


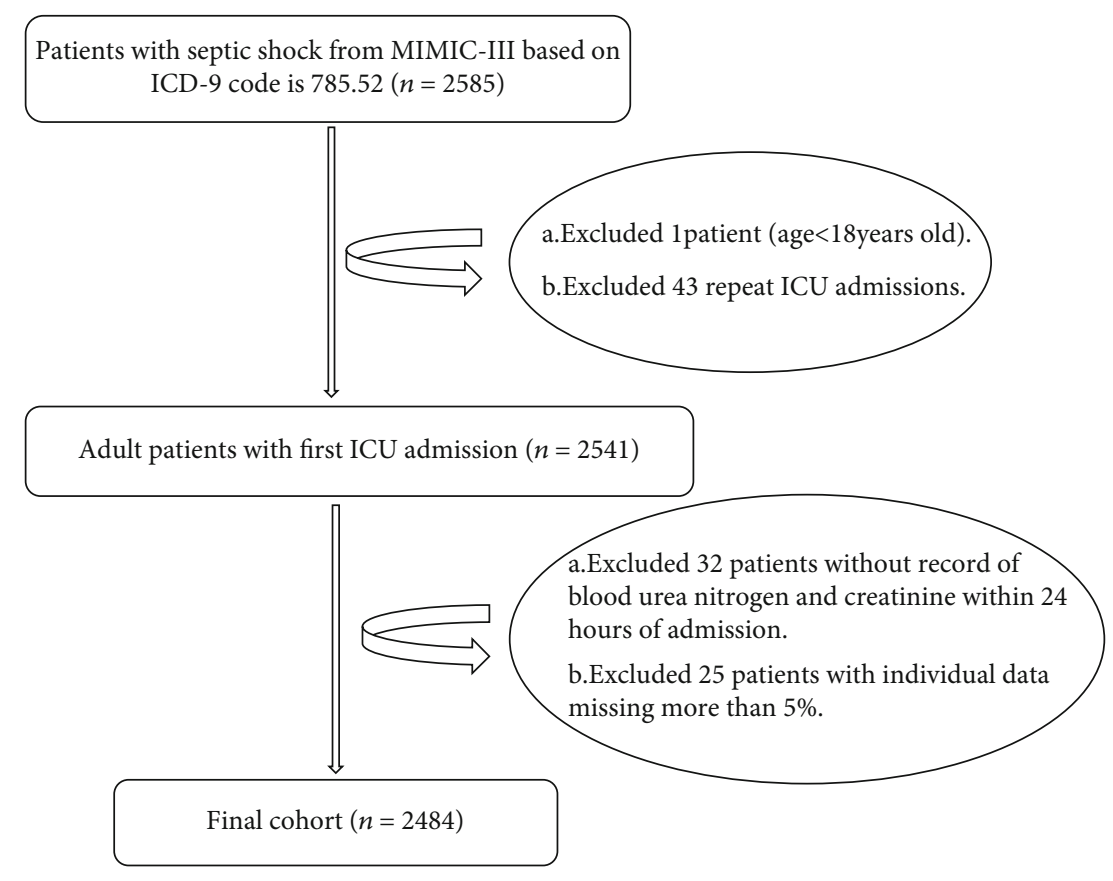

FIgURE 1: Flowchart of study patient selection.

to reduce disease mortality [9]. Despite this, septic shock mortality remains high.

Blood urea nitrogen (BUN) and creatinine (Cr) can reflect the degree of damage to glomerular filtration function caused by external factors from the kidney. An increase in BUN often indicates the presence of a pathological condition, which is common in gastrointestinal bleeding. Intestinal bleeding results in more red blood cells being produced, and plasma proteins can be converted into a nitrogen source and absorbed into the blood. Clinically, $\mathrm{Cr}$ content is often used to detect changes in renal function, which helps to determine whether renal function is in a potential failure state or improved state. Many factors influence BUN and Cr levels $[10,11]$. BUN is not a specific marker of renal insufficiency, and so predictions based on one of BUN or $\mathrm{Cr}$ alone may have limitations.

The BUN/Cr ratio (BCR) has recently been confirmed as a prognostic factor in patients with acute kidney injury, acute cerebral infarction, ischemic stroke, and acute decompensated heart failure [12-15]. However, no previous studies have determined the relationship between the BCR and the prognosis of septic shock patients. This retrospective cohort study is aimed at identifying the relationship between BCR and all-cause mortality in septic shock patients.

\section{Materials and Methods}

2.1. The MIMIC-III Database. This study included 2484 critically ill patients. The study data were extracted from the MIMIC-III database, which is a large, single-center, publicly available critical-care database [16]. It contains unconfirmed health-related data of more than 60,000 ICU patients between 2001 and 2012. The variables recorded in this database are demographics, vital signs, laboratory tests, medica- tions, nursing progress records, and other related clinical variables. The MIMIC-III database was constructed by a collaborative research team at the Laboratory for Computational Physiology, Massachusetts Institute of Technology. To get access to the database, we complete the course "Protecting Human Research Participants" at the website of National Institutes of Health and obtained the certification (Record ID: 38292153) [17].

2.2. Study Population Selection and Data Extraction. Inclusion criteria included (1) patients over 18 years old, (2) patients diagnosed with septic shock according to the International Classification of Diseases 9 code (ICD-9) which is 785.52, and (3) patients who were hospitalized for the first time in the ICU for more than 2 days. Exclusion criteria included (1) BUN and Cr levels not measured during ICU hospitalization and (2) an individual data loss exceeding $5 \%$. (More than $5 \%$ of the patient's clinical research information is missing.)

Demographics, vital signs, comorbidities, laboratory parameters, clinical severity scores, and other admission data were extracted. Comorbidities such as chronic lung, arrhythmia, coagulopathy, congestive heart failure $(\mathrm{CHF})$, diabetes, electrolytes, hypertension, liver disease, and renal failure were also included in this study. Laboratory measurements were included for hemoglobin, hematocrit, platelets, prothrombin time (PT), partial thrombin time (PTT), red blood cell distribution width (RDW), lactate, international normal ratio (INR), anion gap, glucose, albumin, bicarbonate, bilirubin, sodium, potassium, calcium, BUN, $\mathrm{Cr}$, white blood cell count (WBC), lymphocytes, and neutrophils. The Sequential Organ Failure Assessment (SOFA) score and Elixhauser score were extracted for each patient. Also extracted were age, sex, race, marital status, insurance 
TABLE 1: Characteristics of the study patients according to BCR.

\begin{tabular}{|c|c|c|c|c|c|c|}
\hline \multirow{2}{*}{ Variables } & & \multicolumn{4}{|c|}{ BCR } & \multirow{2}{*}{$P$} \\
\hline & & $<14.4$ & $\geq 14.4,<20.0$ & $\geq 20.0,<27.3$ & $\geq 27.3$ & \\
\hline Total & $N=2484$ & $N=619$ & $N=563$ & $N=677$ & $N=625$ & \\
\hline Gender, $n(\%)$ & & & & & & 0.016 \\
\hline Male & $1336(53.8)$ & $364(58.8)$ & $302(53.6)$ & $358(52.9)$ & $312(49.9)$ & \\
\hline Female & $1148(46.2)$ & $255(41.2)$ & $261(46.4)$ & $319(47.1)$ & $313(50.1)$ & \\
\hline \multicolumn{7}{|l|}{ Ethnicity, $n(\%)$} \\
\hline White & $1857(74.8)$ & $388(62.7)$ & $445(79.0)$ & $525(77.5)$ & $499(79.8)$ & $<0.001$ \\
\hline Black & $262(10.5)$ & $130(21.0)$ & $39(6.93)$ & $50(7.39)$ & $43(6.88)$ & \\
\hline Other & 365 (14.7) & $101(16.3)$ & $79(14.0)$ & $102(15.1)$ & $83(13.3)$ & \\
\hline \multicolumn{7}{|l|}{ Insurance, $n(\%)$} \\
\hline Government & $47(1.9)$ & $21(3.39)$ & $11(1.95)$ & $8(1.18)$ & $7(1.12)$ & \\
\hline Medicaid & $192(7.7)$ & $68(11.0)$ & $35(6.22)$ & $43(6.35)$ & $46(7.36)$ & \\
\hline Medicare & $1617(65.1)$ & $343(55.4)$ & $350(62.2)$ & $474(70.0)$ & $450(72.0)$ & $<0.001$ \\
\hline Private & $618(24.9)$ & $184(29.7)$ & $165(29.3)$ & $148(21.9)$ & $121(19.4)$ & \\
\hline Self-pay & $10(0.4)$ & $3(0.48)$ & $2(0.36)$ & $4(0.59)$ & $1(0.16)$ & \\
\hline \multicolumn{7}{|l|}{ Marital status, $n(\%)$} \\
\hline Married & $1774(71.4)$ & $400(64.6)$ & 405 (71.9) & $515(76.1)$ & $454(72.6)$ & $<0.001$ \\
\hline Unmarried & $690(27.8)$ & $216(34.9)$ & $151(26.8)$ & $154(22.7)$ & $169(27.0)$ & \\
\hline Other & $20(0.80)$ & $3(0.48)$ & $7(1.24)$ & $8(1.18)$ & $2(0.32)$ & \\
\hline RRT, $n(\%)$ & & & & & & $<0.001$ \\
\hline Yes & $2253(90.7)$ & $456(73.7)$ & $527(93.6)$ & $663(97.9)$ & $607(97.1)$ & \\
\hline No & $231(9.3)$ & $163(26.3)$ & $36(6.39)$ & $14(2.07)$ & $18(2.88)$ & \\
\hline Mech. vent, $n(\%)$ & & & & & & 0.108 \\
\hline Yes & $1065(42.9)$ & $283(45.7)$ & $241(42.8)$ & $297(43.9)$ & $244(39.0)$ & \\
\hline No & $1419(57.1)$ & $336(54.3)$ & $322(57.2)$ & $380(56.1)$ & $381(61.0)$ & \\
\hline Chronic pulmonary, $n(\%)$ & & & & & & 0.799 \\
\hline Yes & $1889(76.0)$ & $472(76.3)$ & $434(77.1)$ & $506(74.7)$ & $477(76.3)$ & \\
\hline No & $595(24.0)$ & $147(23.7)$ & $129(22.9)$ & $171(25.3)$ & $148(23.7)$ & \\
\hline Cardiac arrhythmias, $n(\%)$ & & & & & & 0.961 \\
\hline Yes & $1418(58.1)$ & $355(57.4)$ & $323(57.4)$ & $389(57.5)$ & $351(56.2)$ & \\
\hline No & $1066(42.9)$ & $264(42.6)$ & $240(42.6)$ & $288(42.5)$ & $274(43.8)$ & \\
\hline Coagulopathy, $n(\%)$ & & & & & & 0.924 \\
\hline Yes & $1710(69.8)$ & $425(68.7)$ & $394(70.0)$ & $462(68.2)$ & $429(68.6)$ & \\
\hline No & $774(31.2)$ & $194(31.3)$ & $169(30.0)$ & $215(31.8)$ & $196(31.4)$ & \\
\hline $\mathrm{CHF}, n(\%)$ & & & & & & 0.731 \\
\hline Yes & $1533(61.7)$ & $373(60.3)$ & $344(61.1)$ & $421(62.2)$ & $395(63.2)$ & \\
\hline No & $951(38.3)$ & $246(39.7)$ & $219(38.9)$ & $256(37.8)$ & $230(36.8)$ & \\
\hline Diabetes, $n(\%)$ & & & & & & 0.174 \\
\hline Yes & $1883(75.8)$ & $474(76.6)$ & $440(78.2)$ & $514(75.9)$ & $455(72.8)$ & \\
\hline No & $601(24.2)$ & $145(23.4)$ & $123(21.8)$ & $163(24.1)$ & $170(27.2)$ & \\
\hline Fluid electrolyte, $n(\%)$ & & & & & & 0.498 \\
\hline Yes & $1034(41.6)$ & $258(41.7)$ & $243(43.2)$ & $266(39.3)$ & $267(42.7)$ & \\
\hline No & $1450(58.4)$ & $361(58.3)$ & $320(56.8)$ & $411(60.7)$ & $358(57.3)$ & \\
\hline Hypertension, $n(\%)$ & & & & & & 0.526 \\
\hline Yes & $1171(47.1)$ & $294(47.5)$ & $279(49.6)$ & $314(46.4)$ & $284(45.4)$ & \\
\hline No & $1313(52.9)$ & $325(52.5)$ & $284(50.4)$ & $363(53.6)$ & $341(54.6)$ & \\
\hline Liver disease, $n(\%)$ & & & & & & 0.628 \\
\hline Yes & $1942(79.2)$ & $477(77.1)$ & $446(79.2)$ & $537(79.3)$ & $482(77.1)$ & \\
\hline No & $542(21.8)$ & $142(22.9)$ & $117(20.8)$ & $140(20.7)$ & $143(22.9)$ & \\
\hline
\end{tabular}


TABLE 1: Continued.

\begin{tabular}{|c|c|c|c|c|c|c|}
\hline \multirow{2}{*}{ Variables } & & \multicolumn{4}{|c|}{ BCR } & \multirow{2}{*}{$P$} \\
\hline & & $<14.4$ & $\geq 14.4,<20.0$ & $\geq 20.0,<27.3$ & $\geq 27.3$ & \\
\hline Renal failure, $n(\%)$ & & & & & & 0.562 \\
\hline Yes & $1868(75.2)$ & $465(75.1)$ & $416(73.9)$ & $522(77.1)$ & $465(74.4)$ & \\
\hline No & $616(24.8)$ & $154(24.9)$ & $147(26.1)$ & $155(22.9)$ & $160(25.6)$ & \\
\hline Age (year) & $67.7(15.8)$ & $60.7(15.7)$ & $68.2(15.1)$ & $70.5(15.2)$ & $71.0(14.9)$ & $<0.001$ \\
\hline PT (second) & $18.7(12.1)$ & $19.6(13.2)$ & $18.6(10.6)$ & $18.3(12.2)$ & $18.5(12.3)$ & 0.184 \\
\hline PTT (second) & $38.0(21.2)$ & $40.0(22.6)$ & $37.9(20.6)$ & $37.2(21.0)$ & $36.9(20.4)$ & 0.039 \\
\hline INR & $1.88(2.12)$ & $2.05(3.14)$ & $1.84(1.39)$ & $1.81(1.76)$ & $1.82(1.73)$ & 0.123 \\
\hline RDW & $16.0(2.43)$ & $16.1(2.45)$ & $15.6(2.24)$ & $15.8(2.37)$ & $16.6(2.55)$ & $<0.001$ \\
\hline $\mathrm{SpO}_{2}(\%)$ & $96.4(4.18)$ & $96.1(4.94)$ & $96.3(3.97)$ & $96.5(3.48)$ & $96.6(4.24)$ & 0.253 \\
\hline Temperature $\left({ }^{\circ} \mathrm{C}\right)$ & $36.8(0.83)$ & $36.9(0.85)$ & $36.8(0.86)$ & $36.8(0.80)$ & $36.7(0.80)$ & $<0.001$ \\
\hline BMI $\left(\mathrm{kg} / \mathrm{m}^{2}\right)$ & $28.5(8.21)$ & $29.2(8.34)$ & $29.5(8.45)$ & $28.2(8.16)$ & $27.3(7.75)$ & $<0.001$ \\
\hline WBC $\left(10^{9 /} \mathrm{L}\right)$ & $14.0(10.3)$ & $13.7(9.35)$ & $13.6(9.85)$ & $14.2(11.6)$ & $14.3(9.95)$ & 0.611 \\
\hline SOFA & $7.82(3.92)$ & $8.52(3.98)$ & $7.77(3.94)$ & $7.61(3.97)$ & $7.42(3.70)$ & $<0.001$ \\
\hline Glucose (mg/dL) & $144.5(52.9)$ & $141(51.6)$ & $145(57.4)$ & $147(54.5)$ & $145(47.8)$ & 0.251 \\
\hline Heart rate (beats/minute) & $92.5(17.9)$ & $93.5(18.2)$ & $92.3(18.1)$ & $92.5(17.4)$ & $91.6(17.9)$ & 0.315 \\
\hline $\mathrm{MBP}(\mathrm{mmHg})$ & $70.98(9.18)$ & $71.7(10.0)$ & $70.9(8.54)$ & $71.0(8.74)$ & $70.3(9.26)$ & 0.077 \\
\hline Respiratory rate (beats/minute) & $21.4(4.72)$ & $21.3(4.83)$ & $21.5(4.35)$ & $21.7(4.85)$ & $21.3(4.78)$ & 0.292 \\
\hline Albumin (g/dL) & $2.82(0.68)$ & $2.90(0.70)$ & $2.85(0.66)$ & $2.85(0.66)$ & $2.69(0.67)$ & $<0.001$ \\
\hline Bilirubin (mg/dL) & $1.98(4.12)$ & $2.02(3.81)$ & $1.73(3.46)$ & $1.82(3.96)$ & $2.34(5.02)$ & 0.048 \\
\hline Bicarbonate $(\mathrm{mg} / \mathrm{dL})$ & $22.3(5.69)$ & $22.1(5.61)$ & $21.4(5.25)$ & $21.9(5.39)$ & $23.7(6.22)$ & $<0.001$ \\
\hline Calcium $(\mathrm{mmol} / \mathrm{L})$ & $8.10(1.09)$ & $8.03(1.16)$ & $8.03(1.05)$ & $8.17(1.06)$ & $8.18(1.10)$ & 0.010 \\
\hline Potassium $(\mathrm{mmol} / \mathrm{L})$ & $4.41(1.00)$ & $4.31(1.06)$ & $4.37(0.94)$ & $4.43(0.96)$ & $4.52(1.02)$ & 0.002 \\
\hline Sodium (mmol/L) & $137.57(6.89)$ & $137(5.50)$ & $137(6.14)$ & $137(6.75)$ & $139(8.61)$ & $<0.001$ \\
\hline Hematocrit (\%) & $33.75(6.45)$ & $34.3(6.39)$ & $34.3(6.26)$ & $33.7(6.37)$ & $32.7(6.65)$ & $<0.001$ \\
\hline Hemoglobin $(\mathrm{g} / \mathrm{dL})$ & $11.11(2.18)$ & $11.2(2.23)$ & $11.3(2.11)$ & $11.2(2.14)$ & $10.7(2.22)$ & $<0.001$ \\
\hline Platelet $\left(10^{9 /} \mathrm{L}\right)$ & $239(153)$ & $223(138)$ & $246(146)$ & $245(162)$ & $243(161)$ & 0.022 \\
\hline Lactate $(\mathrm{mmol} / \mathrm{L})$ & $3.12(2.38)$ & $3.48(2.97)$ & $3.29(2.43)$ & $3.07(2.14)$ & $2.69(1.79)$ & $<0.001$ \\
\hline Anion gap $(\mathrm{mmol} / \mathrm{L})$ & $17.32(5.08)$ & $18.4(5.49)$ & $17.6(5.09)$ & $17.3(4.81)$ & $16.0(4.62)$ & $<0.001$ \\
\hline Lymphocytes (\%) & $10.6(11.9)$ & $10.5(10.6)$ & $11.0(12.3)$ & $10.7(12.9)$ & $10.3(11.7)$ & 0.780 \\
\hline Neutrophils (\%) & $76.9(18.2)$ & $76.7(17.3)$ & $76.0(18.0)$ & $76.9(19.1)$ & $77.7(18.2)$ & 0.456 \\
\hline Hours of vasopressor & $67.5(96.2)$ & $72.1(103)$ & $65.3(100)$ & $62.5(90.4)$ & $70.5(91.4)$ & 0.250 \\
\hline ICU LOS (day) & $7.76(9.71)$ & $7.61(9.44)$ & $7.91(10.14)$ & $7.20(8.49)$ & $8.40(10.72)$ & 0.154 \\
\hline Hospital LOS (day) & $7.75(9.70)$ & $7.58(9.44)$ & $7.90(10.14)$ & $7.18(8.49)$ & $8.39(10.73)$ & 0.148 \\
\hline 28-day mortality, $n(\%)$ & $936(37.7)$ & 215 & $183(32.5)$ & $237(35.0)$ & $301(48.2)$ & $<0.001$ \\
\hline 90-day mortality, $n(\%)$ & $1757(70.7)$ & $424(68.5)$ & $389(69.1)$ & $465(68.7)$ & $479(76.6)$ & 0.003 \\
\hline 365-day mortality, $n(\%)$ & $1983(79.8)$ & $485(78.4)$ & $440(78.2)$ & $524(77.4)$ & $534(85.4)$ & 0.001 \\
\hline
\end{tabular}

BCR: blood urea nitrogen/creatinine ratio; RRT: renal replacement therapy; CHF: congestive heart failure; PT: prothrombin time; PTT: partial thrombin time; RDW: red blood cell distribution width; INR: international normal ratio; BMI: body mass index; WBC: white blood cell count; SOFA: Sequential Organ Failure Assessment score; MBP: mean blood pressure; ICU: intensive care unit; LOS: length of stay.

status, admission type, mean blood pressure (MBP), temperature, heart rate, $\mathrm{SpO}_{2}$, respiratory rate, renal replacement therapy (RRT) use, mechanical ventilation use, hours of vasopressor use, and length of stay in the ICU. If the above laboratory parameters were tested multiple times within 24 hours, BCR is calculated according to the first test [18]. Patients were divided into four quartile groups based on the initial BCR value. The main endpoint was 28-day all-cause mortality, while the 90- and 365-day all-cause mortality rates were also study outcomes.
2.3. Statistical Analysis. The baseline characteristics of all patients were stratified according to BCR quartiles. Normally distributed continuous variables were reported as the means $\pm S D$, whereas nonnormal variables were summarized as the median and interquartile range (IQR). Shapiro-Wilk tests were used to assess variable distributions. Categorical variables were expressed as frequencies and proportions and compared using chi-square tests and Fisher's exact test [19]. Log-rank testing was used to compare survival rates, and Kaplan-Meier curves were constructed [20]. Multivariate 


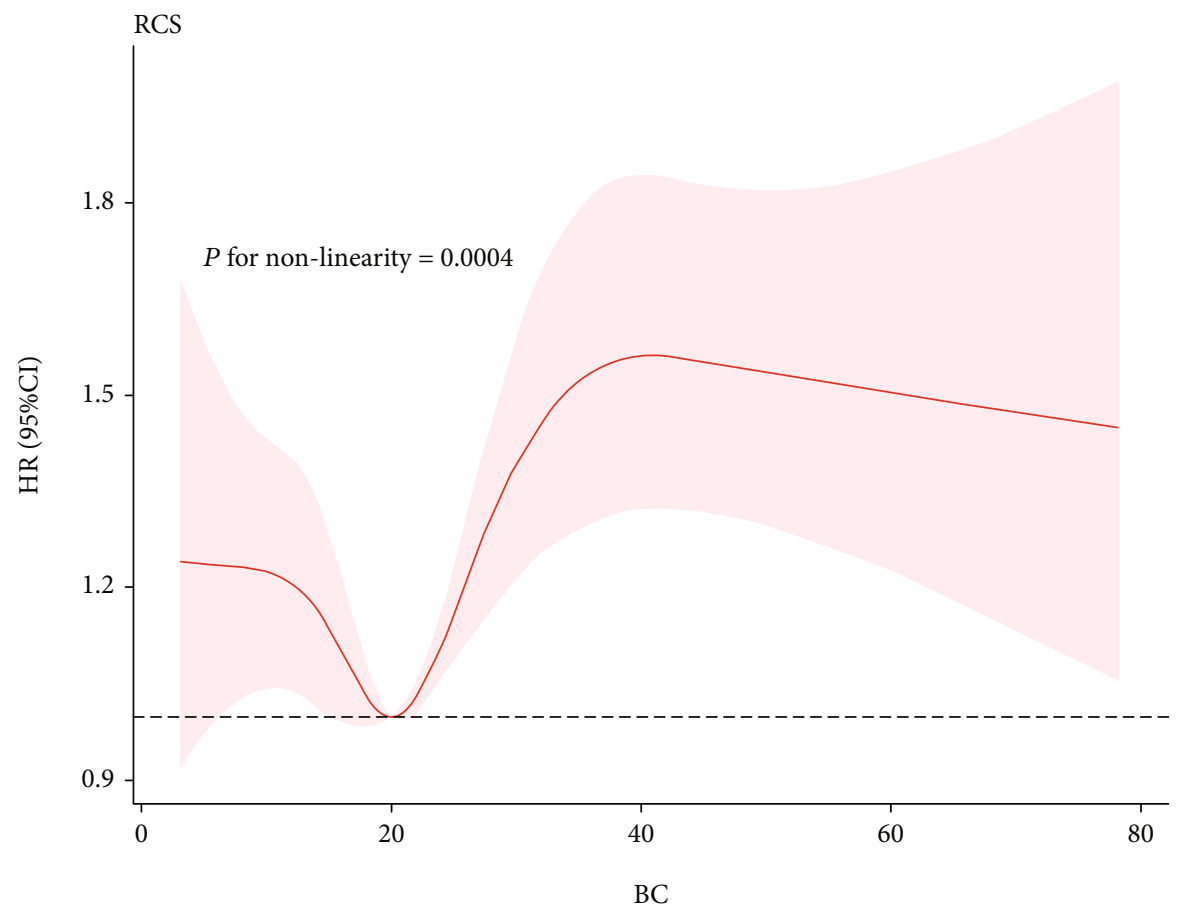

FIGURE 2: Nonparametric estimates of all-cause mortality on BCR among patients with septic shock.

Cox proportional hazards regression was used to determine the relationship between BCR and 28-, 90-, and 365-day all-cause mortality rates. The results of these were expressed as hazard ratios (HRs) with 95\% confidence intervals (CIs). Results were analyzed separately according to the cutoff value of BCRs obtained from a curve-fitting method [21].

We established two multivariate models to determine whether BCR is independently related to the outcome endpoint. In model I, covariates were only adjusted for age, sex, race, marital status, and insurance status [20]. In model II, we adjusted for age, sex, Elixhauser score, RRT use, mechanical ventilation use, chronic pulmonary, CHF, diabetes, fluid electrolyte, liver disease, renal failure, temperature, heart rate, hematocrit, platelets, glucose, SOFA score, $\mathrm{MBP}, \mathrm{SpO}_{2}, \mathrm{PT}$, lactate, albumin, bicarbonate, bilirubin, potassium, and calcium. We select these confounding factors based on the estimated impact of changes over $10 \%$. Subgroup analysis of the associations between BCRs and 28-day all-cause mortality was performed using stratified linear regression models. Receiver operator characteristic (ROC) curve analysis is used to further evaluate the accuracy of BCRs [18].

All statistical analysis was performed using SPSS (version 21.0) and $\mathrm{R}$ software (version 3.6.1). Missing values were addressed using multiple imputation during Cox regression and model construction [22]. A two-tailed $P$ value of $<0.05$ was considered statistically significant.

\section{Results}

3.1. Population and Baseline Characteristics. Data included within 24 hours of admission from 2484 eligible septic shock patients were included in this study. The data selection procedure is displayed in Figure 1. Patient demographic charac- teristics stratified by BCR quartiles are listed in Table 1 . The patients were aged $67.7 \pm 15.8$ years and comprised 1136 (53.8\%) males and 1857 (74.8\%) white patients. Emergency admission accounted for 2389 (96.2\%) patients, 1617 (65.1\%) had Medicare insurance, and 1774 (71.4\%) were married. RRT was performed on 2253 (90.7\%) patients, and 1419 (42.9\%) were treated using mechanical ventilation.

According to BCR, 619, 563, 677, and 625 patients belonged to the first $(<14.4 \mathrm{mg} / \mathrm{dL})$, second $(\geq 14.4 \mathrm{mg} / \mathrm{dL}$ and $<20.0 \mathrm{mg} / \mathrm{dL})$, third $(\geq 20.0 \mathrm{mg} / \mathrm{dL}$ and $<27.3 \mathrm{mg} / \mathrm{dL})$, and fourth $(\geq 27.3 \mathrm{mg} / \mathrm{dL})$ quartiles, respectively. Patients with $\mathrm{BCR} \geq 27.3 \mathrm{mg} / \mathrm{dL}$ were more likely to be female and elderly, were more likely to have comorbidities including $\mathrm{CHF}$ and fluid electrolyte imbalance, and had lower values of MBP, BMI, INR, heart rate, temperature, respiratory rate, anion gap, lactate, albumin, hematocrit, and hemoglobin and higher WBC, SOFA score, RDW, $\mathrm{SpO}_{2}$, sodium, potassium, calcium, bicarbonate, bilirubin, and mortality.

3.2. Association between BUN/Cr and Mortality. The Cox proportional hazards regression model was used to determine the relationship between BCR and all-cause mortality in septic shock patients. We observed that BCR value and septic shock patient mortality had an M-shaped relationship (Figure 2). The Kaplan-Meier curve in Figure 3 displays the relationship between BCR quartiles and 28-, 90-, and 365day mortality.

The first quartile BCR was used as a reference in model I and model II. In model I, higher BCR (fourth quartile vs. first quartile) was associated with increased risks of 28-, 90-, and 365-day all-cause mortality after adjusting for age, sex, race, marital status, and insurance status $(\mathrm{HR}=1.281,95 \% \mathrm{CI}=$ $1.066-1.540, P=0.008 ; \mathrm{HR}=1.385,95 \% \mathrm{CI}=1.175-1.633$, 

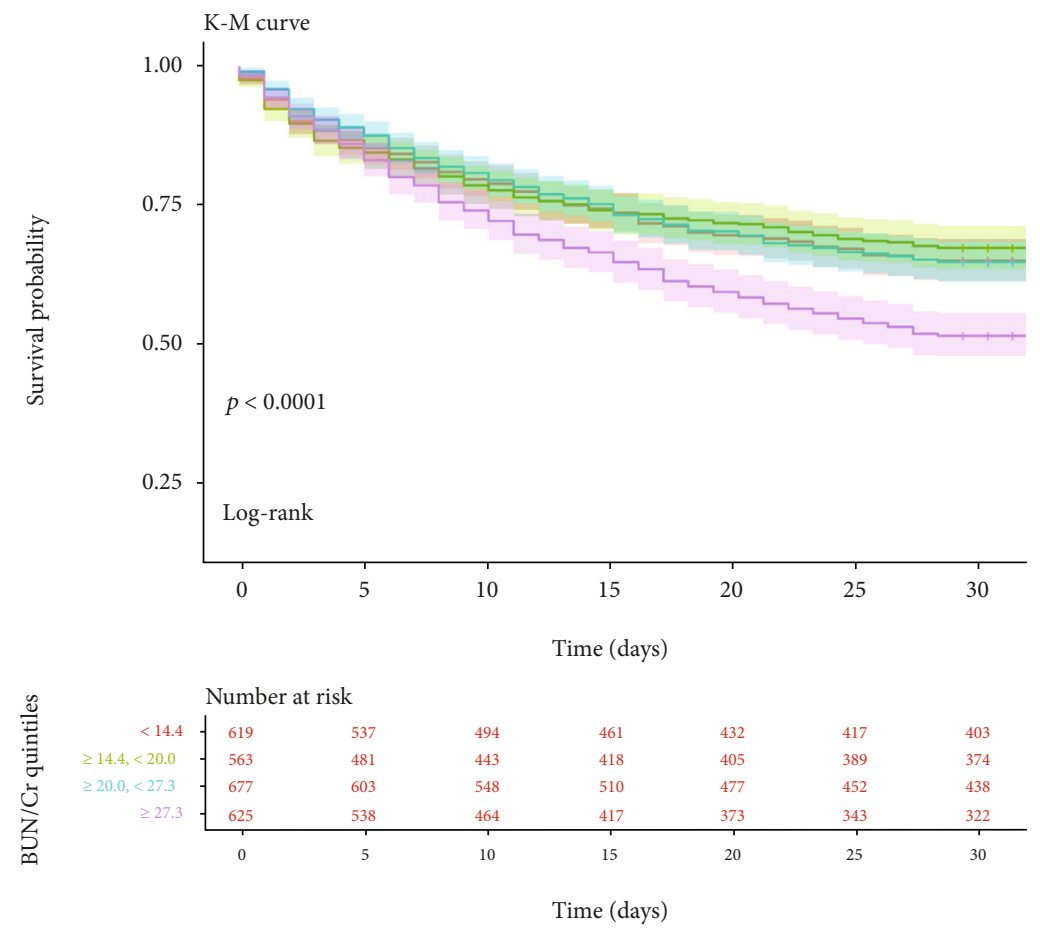

\begin{tabular}{|c|c|}
\hline BUN/Cr quintiles & $\Psi \geq 20.0,<27.3$ \\
\hline$+<14.4$ & $\mp \geq 27.3$ \\
\hline
\end{tabular}

(a)
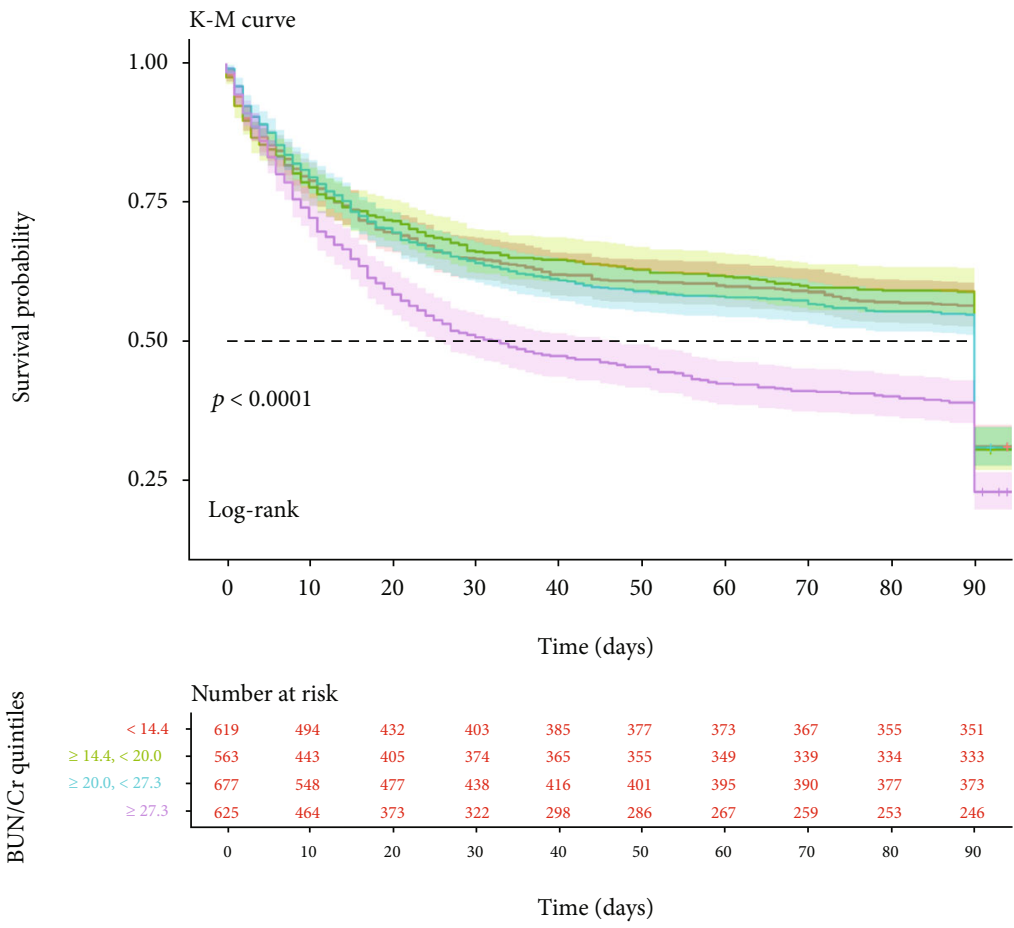

$\begin{array}{ll}\text { BUN/Cr quintiles } & \square \geq 20.0,<27.3 \\ \square<14.4 & \square \geq 27.3\end{array}$

(b)

Figure 3: Continued. 

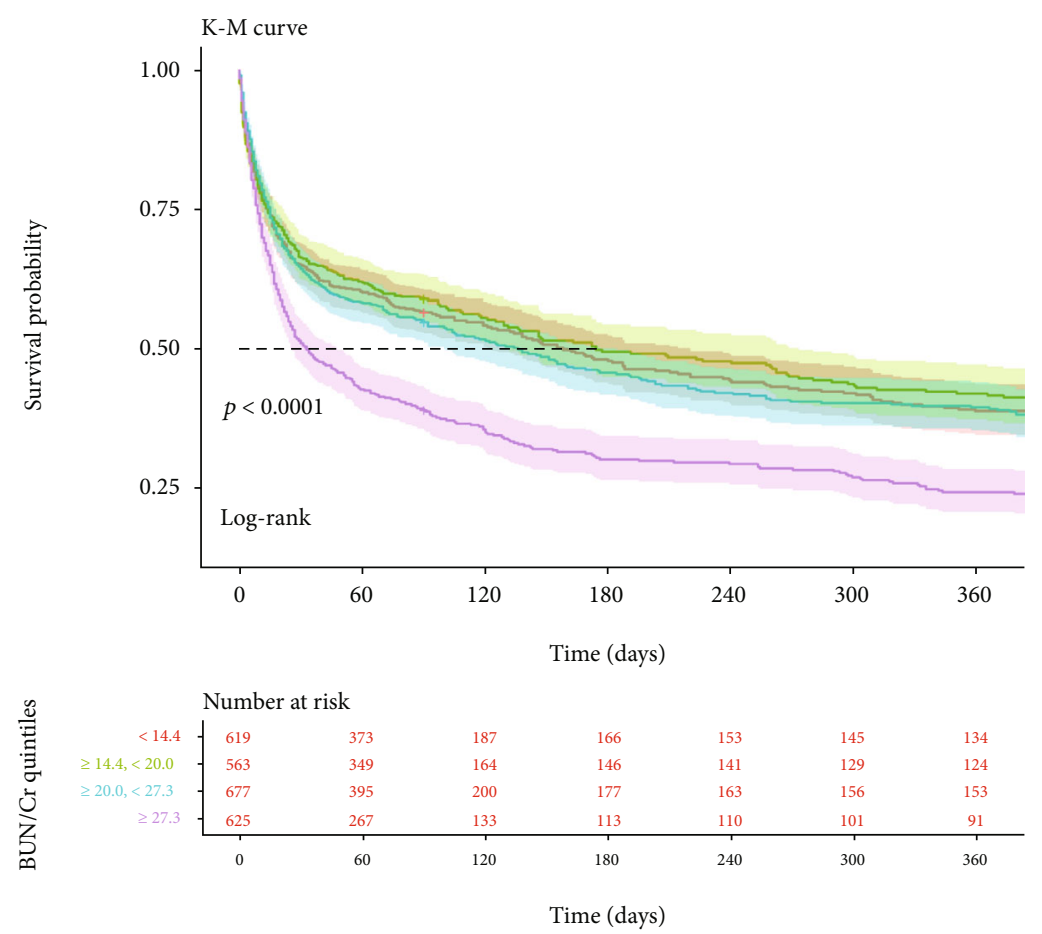

$\begin{array}{ll}\text { BUN/Cr quintiles } & \Psi \geq 20.0,<27.3 \\ +<14.4 & +\geq 27.3 \\ +\geq 14.4,<20.0 & \end{array}$

(c)

FIGURE 3: Kaplan-Meier curves showing the association between the BCR quartiles and all-cause mortality: (a) 28-day mortality; (b) 90-day mortality; (c) 365-day mortality.

$P<0.001 ;$ and $\mathrm{HR}=1.324,95 \% \mathrm{CI}=1.139-1.540, P<0.001$ , respectively). In model II, after adjustment for confounders including age, sex, Elixhauser score, RRT use, mechanical ventilation use, chronic pulmonary, $\mathrm{CHF}$, diabetes, fluid electrolyte, liver disease, renal failure, temperature, heart rate, hematocrit, platelets, glucose, SOFA score, $\mathrm{MBP}, \mathrm{SpO}_{2}, \mathrm{PT}$, lactate, albumin, bicarbonate, bilirubin, potassium, and calcium, higher BCR was still significantly associated with 28-, 90-, and 365-day all-cause mortality rates (fourth quartile vs. first quartile: $\mathrm{HR}=1.268,95 \% \mathrm{CI}=1.037-1.551, P=0.021$; $\mathrm{HR}=1.344,95 \% \mathrm{CI}=1.124-1.606, P=0.001 ;$ and $\mathrm{HR}=$ $1.309,95 \% \mathrm{CI}=1.113-1.540, P=0.001$, respectively). For the purpose of sensitivity analysis, we also handled BCR as categorical variable (tertiles and quintiles) and found the same trend ( $P$ for trend: $<0.0001)$. The results are listed in Table 2.

3.3. Subgroup Analysis. The association between different BCR levels and the 28-day all-cause mortality in septic shock patients was determined using a subgroup analysis. The significant interactions were PT $(P=0.007)$, MBP $(P=0.037)$, hours of vasopressor $(P=0.013)$, and platelets $(P=0.008)$. Patients who did not receive mechanical ventilation and had BCR $>27.3$ had a higher risk of death at 28 days (HR: 3.467; 95\% CI: 1.883-6.558; $P<0.001)$. Similarly, patients with temperature $<36.7^{\circ} \mathrm{C}$, albumin $<2.7 \mathrm{~g} / \mathrm{dL}$, anion gap $<$ 15 , and $\mathrm{RDW} \geq 15.4$ showed an increased risk with a BCR $\geq 27.3$ (HR, 95\% CI, P: 1.612, 1.070-2.428; 1.538, 1.004$2.355 ; 1.700,1.052-2.748 ; 1.678,1.089-2.585$, respectively). All results are presented in Table 3 .

3.4. ROC Curve Analysis. The sensitivity and specificity of BCR and other variables (SOFA score, BCR plus SOFA score, APSIII, and BCR plus APSIII) were tested using ROC curves. Meanwhile, the area under the ROC curve (AUC) was calculated to evaluate the predictive performance of BCR for 28-, 90-, and 365-day all-cause mortality.

For the 28-day endpoint, the AUC was 0.676 (95\% CI: 0.655-0.698) for the SOFA score, 0.694 (95\% CI: $0.673-$ 0.716 ) for BCR plus SOFA score, 0.716 (95\% CI: $0.691-$ 0.741 ) for APSIII, and 0.724 (95\% CI: 0.703-0.744) for BCR plus APSIII. The generated ROC curves for 28-, 90-, and 365-day all-cause mortality are displayed in Figure 4.

\section{Discussion}

We studied 2484 septic shock patients to determine the relationships between BCR and 28-, 90-, and 365-day allcause mortality rates. We found that compared with the preadmission first quartile $(\mathrm{BCR}<14.4 \mathrm{mg} / \mathrm{dL})$, high $\mathrm{BCR}$ $(\geq 27.3 \mathrm{mg} / \mathrm{dL})$ in septic shock patients within 24 hours of admission was significantly associated with all-cause mortality. After adjusting for age, sex, race, and other confounding 
TABLE 2: HRs (95\% CIs) for all-cause mortality across groups of BCR.

\begin{tabular}{|c|c|c|c|c|c|c|c|c|c|}
\hline \multirow{2}{*}{ Variables } & \multicolumn{3}{|c|}{ Nonadjusted } & \multicolumn{3}{|c|}{ Model I } & \multicolumn{3}{|c|}{ Model II } \\
\hline & HR & $95 \%$ CI & $P$ value & HR & $95 \% \mathrm{CI}$ & $P$ value & HR & $95 \% \mathrm{CI}$ & $P$ value \\
\hline \multicolumn{10}{|c|}{ 28-day all-cause mortality } \\
\hline BCR & 1.011 & $1.006-1.016$ & $<0.001$ & 1.009 & $1.004-1.014$ & $<0.001$ & 1.007 & $1.002-1.013$ & 0.013 \\
\hline \multicolumn{10}{|l|}{ Tertiles } \\
\hline$<16.3$ & Reference & & & Reference & & & Reference & & \\
\hline$\geq 16.3,<24.3$ & 1.032 & $0.875-1.218$ & 0.708 & 0.911 & $0.768-1.081$ & 0.286 & 0.990 & $0.827-1.186$ & 0.913 \\
\hline$\geq 24.3$ & 1.390 & $1.190-1.624$ & $<0.001$ & 1.220 & $1.037-1.436$ & 0.016 & 1.186 & $0.993-1.416$ & 0.060 \\
\hline$P$ for trend & $<0.0001$ & & & $<0.0001$ & & & $<0.0001$ & & \\
\hline \multicolumn{10}{|l|}{ Quartiles } \\
\hline$<14.4$ & Reference & & & Reference & & & Reference & & \\
\hline$\geq 14.4,<20.0$ & 0.937 & $0.769-1.141$ & 0.516 & 0.842 & $0.688-1.031$ & 0.096 & 0.969 & $0.785-1.195$ & 0.766 \\
\hline$\geq 20.0,<27.3$ & 0.996 & $0.828-1.198$ & 0.969 & 0.862 & $0.710-1.042$ & 0.124 & 0.942 & $0.767-1.157$ & 0.571 \\
\hline$\geq 27.3$ & 1.485 & $1.246-1.769$ & $<0.001$ & 1.281 & $1.066-1.540$ & 0.008 & 1.268 & $1.037-1.551$ & 0.021 \\
\hline$P$ for trend & $<0.0001$ & & & $<0.0001$ & & & $<0.0001$ & & \\
\hline \multicolumn{10}{|l|}{ Quintiles } \\
\hline$<13.3$ & Reference & & & Reference & & & Reference & & \\
\hline$\geq 13.3,<17.7$ & 0.810 & $0.652-1.004$ & 0.055 & 0.744 & $0.597-0.928$ & 0.009 & 0.903 & $0.718-1.136$ & 0.385 \\
\hline$\geq 17.7,<22.5$ & 0.911 & $0.738-1.124$ & 0.385 & 0.775 & $0.623-0.963$ & 0.022 & 0.996 & $0.791-1.253$ & 0.970 \\
\hline$\geq 22.5,<30.0$ & 1.036 & $0.846-1.270$ & 0.731 & 0.879 & $0.711-1.087$ & 0.233 & 0.921 & $0.733-1.156$ & 0.477 \\
\hline$\geq 30.0$ & 1.403 & $1.158-1.699$ & $<0.001$ & 1.203 & $0.984-1.471$ & 0.071 & 1.247 & $1.002-1.552$ & 0.047 \\
\hline$P$ for trend & $<0.0001$ & & & $<0.0001$ & & & $<0.0001$ & & \\
\hline \multicolumn{10}{|c|}{ 90-day all-cause mortality } \\
\hline BCR & 1.013 & $1.009-1.017$ & $<0.001$ & 1.012 & $1.008-1.016$ & $<0.001$ & 1.009 & $1.005-1.014$ & $<0.001$ \\
\hline \multicolumn{10}{|l|}{ Tertiles } \\
\hline$<16.3$ & Reference & & & Reference & & & Reference & & \\
\hline$\geq 16.3,<24.3$ & 1.026 & $0.886-1.189$ & 0.729 & 0.913 & $0.784-1.063$ & 0.241 & 0.981 & $0.836-1.151$ & 0.812 \\
\hline$\geq 24.3$ & 1.452 & $1.265-1.666$ & $<0.001$ & 1.285 & $1.113-1.484$ & $<0.001$ & 1.240 & $1.060-1.450$ & 0.007 \\
\hline$P$ for trend & $<0.0001$ & & & $<0.0001$ & & & $<0.0001$ & & \\
\hline \multicolumn{10}{|l|}{ Quartiles } \\
\hline$<14.4$ & Reference & & & Reference & & & Reference & & \\
\hline$\geq 14.4,<20.0$ & 0.939 & $0.787-1.119$ & 0.481 & 0.858 & $0.716-1.028$ & 0.097 & 0.969 & $0.804-1.167$ & 0.738 \\
\hline$\geq 20.0,<27.3$ & 1.036 & $0.880-1.221$ & 0.670 & 0.904 & $0.763-1.073$ & 0.249 & 0.984 & $0.821-1.179$ & 0.856 \\
\hline$\geq 27.3$ & 1.575 & $1.347-1.841$ & $<0.001$ & 1.385 & $1.175-1.633$ & $<0.001$ & 1.344 & $1.124-1.606$ & 0.001 \\
\hline$P$ for trend & $<0.0001$ & & & $<0.0001$ & & & $<0.0001$ & & \\
\hline \multicolumn{10}{|l|}{ Quintiles } \\
\hline$<13.3$ & Reference & & & Reference & & & Reference & & \\
\hline$\geq 13.3,<17.7$ & 0.853 & $0.705-1.033$ & 0.104 & 0.797 & $0.655-0.969$ & 0.023 & 0.942 & $0.770-1.153$ & 0.564 \\
\hline$\geq 17.7,<22.5$ & 0.906 & $0.750-1.095$ & 0.308 & 0.784 & $0.644-0.954$ & 0.015 & 0.977 & $0.796-1.200$ & 0.824 \\
\hline$\geq 22.5,<30.0$ & 1.073 & $0.894-1.288$ & 0.447 & 0.921 & $0.761-1.115$ & 0.400 & 0.967 & $0.789-1.184$ & 0.742 \\
\hline$\geq 30.0$ & 1.552 & $1.309-1.841$ & $<0.001$ & 1.358 & $1.135-1.626$ & $<0.001$ & 1.377 & $1.134-1.671$ & 0.001 \\
\hline$P$ for trend & $<0.0001$ & & & $<0.0001$ & & & $<0.0001$ & & \\
\hline \multicolumn{10}{|c|}{ 365-day all-cause mortality } \\
\hline BCR & 1.012 & $1.009-1.016$ & $<0.001$ & 1.010 & $1.007-1.014$ & $<0.001$ & 1.008 & $1.004-1.013$ & $<0.001$ \\
\hline \multicolumn{10}{|l|}{ Tertiles } \\
\hline$<16.3$ & Reference & & & Reference & & & Reference & & \\
\hline$\geq 16.3,<24.3$ & 1.002 & $0.894-1.168$ & 0.749 & 0.899 & $0.782-1.032$ & 0.131 & 0.956 & $0.827-1.105$ & 0.541 \\
\hline$\geq 24.3$ & 1.415 & $1.247-1.606$ & $<0.001$ & 1.243 & $1.089-1.148$ & $<0.001$ & 1.212 & $1.051-1.397$ & 0.008 \\
\hline$P$ for trend & $<0.0001$ & & & $<0.0001$ & & & $<0.0001$ & & \\
\hline
\end{tabular}


TABLE 2: Continued.

\begin{tabular}{|c|c|c|c|c|c|c|c|c|c|}
\hline \multirow{2}{*}{ Variables } & \multicolumn{3}{|c|}{ Nonadjusted } & \multicolumn{3}{|c|}{ Model I } & \multicolumn{3}{|c|}{ Model II } \\
\hline & HR & $95 \%$ CI & $P$ value & HR & $95 \%$ CI & $P$ value & HR & $95 \%$ CI & $P$ value \\
\hline \multicolumn{10}{|l|}{ Quartiles } \\
\hline$<14.4$ & Reference & & & Reference & & & Reference & & \\
\hline$\geq 14.4,<20.0$ & 0.938 & $0.800-1.100$ & 0.432 & 0.848 & $0.721-1.000$ & 0.049 & 0.957 & $0.810-1.133$ & 0.616 \\
\hline$\geq 20.0,<27.3$ & 1.011 & $0.872-1.174$ & 0.881 & 0.874 & $0.748-1.021$ & 0.089 & 0.945 & $0.802-1.112$ & 0.494 \\
\hline$\geq 27.3$ & 1.526 & $1.323-1.761$ & $<0.001$ & 1.324 & $1.139-1.540$ & $<0.001$ & 1.309 & $1.113-1.540$ & 0.001 \\
\hline$P$ for trend & $<0.0001$ & & & $<0.0001$ & & & $<0.0001$ & & \\
\hline \multicolumn{10}{|l|}{ Quintiles } \\
\hline$<13.3$ & Reference & & & Reference & & & Reference & & \\
\hline$\geq 13.3,<17.7$ & 0.865 & $0.728-1.029$ & 0.102 & 0.795 & $0.666-0.950$ & 0.012 & 0.928 & $0.773-1.114$ & 0.422 \\
\hline$\geq 17.7,<22.5$ & 0.934 & $0.786-1.106$ & 0.423 & 0.797 & $0.667-0.952$ & 0.013 & 0.975 & $0.810-1.172$ & 0.784 \\
\hline$\geq 22.5,<30.0$ & 1.029 & $0.870-1.217$ & 0.737 & 0.869 & $0.728-1.036$ & 0.118 & 0.905 & $0.752-1.089$ & 0.291 \\
\hline$\geq 30.0$ & 1.535 & $1.312-1.796$ & $<0.001$ & 1.326 & $1.124-1.564$ & $<0.001$ & 1.364 & $1.143-1.628$ & $<0.001$ \\
\hline$P$ for trend & $<0.0001$ & & & $<0.0001$ & & & $<0.0001$ & & \\
\hline
\end{tabular}

HR: hazard ratio; CI: confidence interval. Models were derived from Cox proportional hazards regression models. Nonadjusted model adjusted for none. Adjust I model adjusted for age, sex, race, marital status, and insurance status. Adjust II model adjusted for age, sex, Elixhauser score, RRT use, mechanical ventilation use, chronic pulmonary, CHF, diabetes, fluid electrolyte, liver disease, renal failure, temperature, heart rate, hematocrit, platelets, glucose, SOFA score, MBP, $\mathrm{SpO}_{2}$, PT, lactate, albumin, bicarbonate, bilirubin, potassium, and calcium.

factors, the study results remained reliable. Higher BCR was associated with an increase in mortality, suggesting that this ratio is a risk factor for the prognosis of septic shock patients. There was a nonlinear (M-shaped) relationship between BCR and mortality in critically ill septic shock patients [17]. To our knowledge, this is the first study of the relationship between BCR and all-cause mortality in septic shock patients.

Septic shock is a human body response to infection caused by abnormal circulation and cell metabolism [1]. The reported prevalence of sepsis is $12 \%$ of all ICU patients in the United States, and the hospital mortality rate for septic shock is approximately 40-60\% [23]. Although the incidence of sepsis is decreasing every year, septic shock mortality rates remain very high [24].

BUN is known to be a risk factor for mortality in many cases, such as acute and chronic heart failure [25], coronary artery bypass grafts [26], acute pancreatitis [27], and bone marrow transplants [28]. BUN is also included in the general severity score of critically ill patients [29]. Changes in Cr concentration were directly related to glomerular filtration rate. When glomerular filtration function decreases, the concentration of serum $\mathrm{Cr}$ increases, indicating kidney damage, but this indicator has a low sensitivity, meaning that when it does rise, kidney function has been severely impaired [30]. Previous studies have found that BCR is a predictor of acute kidney injury and acute heart failure patient prognosis [31-34]. Takaya et al. [31-34] indicated that BCR $\geq 22$ was associated with a poor survival prognosis in acute heart failure patients. Gastrointestinal bleeding can increase catabolism or increase urea absorption in the intestines, leading to increased BUN. This suggests that the higher BCR means a more severe condition.

When septic shock occurs, blood is affected by many inflammatory factors, which can lead to acute kidney injury and even acute renal failure. BUN and Cr levels are commonly used clinical indicators of renal function. Brisco et al. [35] also found that BCR and increased mortality are related, but there have been few studies showing that BCR is related to the prognosis of septic shock patients.

We found that a higher BCR was a risk factor for mortality in septic shock patients. The first quartile was the reference value, and the second and third quartiles had relatively low HR values and hence were protective factors. Regression adjusted for covariates found that the relationship between BCR and prognosis was M-shaped. And we did find that patients included in the group of the highest BCR $(\geq 27.3 \mathrm{mg} / \mathrm{dL})$ have significantly higher 28 -day mortality compared to those of the other three groups. This may be because BCRs in the second and third quartiles are within the normal range, the patient's condition is normal, and the risk of death is low, whereas BCRs that are either too low or too high will increase the risk of death and lead to a poor prognosis. In general, there are two clinical reasons for BCR increasing. One is that only the increase of BUN will cause an increase in BCR when Cr is normal. This can occur during dehydration, blood loss, gastrointestinal bleeding [36], and eating a large amount of high-protein foods [10]. The other is prerenal oliguria, which occurs via a decrease in renal blood circulation, which leads to increases in $\mathrm{Cr}$ and BUN and a decrease in urine output. If BCR decreases, renal oliguria or postrenal oliguria might be present. Recent studies have indicated $\mathrm{BCR} \geq 15 \mathrm{mg} / \mathrm{dL}$ as a precursor to dehydration, which may be related to complications from acute cerebral infarction and early deterioration of neurological function [37, 38]. However, the relationship between this indicator and septic shock has not yet been studied. It is worth noting that our results show a nonlinear relationship between BCR and the prognosis of patients with septic shock.

According to our results, higher BCR worsens the prognosis of septic shock patients, which is consistent with previous studies [35]. Referred to the first quartile, we found that the HR value of the fourth quantiles was greater than 1, 
TABLE 3: Subgroup analysis of the associations between the BCR and 28-day all-cause mortality.

\begin{tabular}{|c|c|c|c|c|c|c|}
\hline \multirow[b]{2}{*}{ Characteristics } & \multirow[b]{2}{*}{ No. of patients } & \multicolumn{4}{|c|}{ BCR } & \multirow[b]{2}{*}{$\begin{array}{c}P \text { for } \\
\text { interaction }\end{array}$} \\
\hline & & $\begin{array}{c}<14.4 \\
\operatorname{HR}(95 \% \mathrm{CI})\end{array}$ & $\begin{array}{l}\geq 14.4,<20.0 \\
\operatorname{HR}(95 \% \mathrm{CI})\end{array}$ & $\begin{array}{c}\geq 20.0,<27.3 \\
\operatorname{HR}(95 \% \mathrm{CI})\end{array}$ & $\begin{aligned} & \geq 27.3 \\
\operatorname{HR} & (95 \% \mathrm{CI})\end{aligned}$ & \\
\hline Age (year) & & & & & & 0.104 \\
\hline$<69$ & 1228 & 1.0 (ref) & $0.824(0.590-1.152)$ & $0.930(0.652-1.326)$ & $1.165(0.709-1.914)$ & \\
\hline$\geq 69$ & 1256 & 1.0 (ref) & $1.130(0.828-1.544)$ & $0.900(0.656-1.236)$ & $1.275(0.858-1.896)$ & \\
\hline Gender & & & & & & 0.867 \\
\hline Male & 1336 & 1.0 (ref) & $0.831(0.616-1.121)$ & $0.853(0.630-1.156)$ & $0.936(0.611-1.433)$ & \\
\hline Female & 1148 & 1.0 (ref) & $1.033(0.733-1.454)$ & $0.849(0.591-1.220)$ & $1.206(0.770-1.889)$ & \\
\hline Ethnicity & & & & & & 0.666 \\
\hline White & 1857 & 1.0 (ref) & $0.974(0.753-1.261)$ & $0.886(0.679-1.155)$ & $0.886(0.679-1.155)$ & \\
\hline Black & 262 & 1.0 (ref) & $0.843(0.341-2.041)$ & $0.482(0.191-1.214)$ & $0.846(0.236-3.037)$ & \\
\hline Other & 365 & 1.0 (ref) & $0.695(0.381-1.266)$ & $0.945(0.498-1.791)$ & $0.631(0.249-1.600)$ & \\
\hline Marital status & & & & & & 0.980 \\
\hline Married & 1774 & 1.0 (ref) & $0.907(0.700-1.175)$ & $0.846(0.629-1.102)$ & $1.144(0.810-1.616)$ & \\
\hline Unmarried & 690 & 1.0 (ref) & $0.907(0.566-1.454)$ & $0.866(0.527-1.423)$ & $1.160(0.594-2.264)$ & \\
\hline Other & 20 & 1.0 (ref) & - & - & - & \\
\hline RRT & & & & & & 0.065 \\
\hline Yes & 231 & 1.0 (ref) & $0.829(0.398-1.726)$ & $0.585(0.130-2.263)$ & $0.714(0.147-3.465)$ & \\
\hline No & 2253 & 1.0 (ref) & $1.050(0.822-1.341)$ & $0.982(0.769-1.255)$ & $1.255(0.913-1.724)$ & \\
\hline Mech. vent & & & & & & 0.484 \\
\hline Yes & 1419 & 1.0 (ref) & $0.884(0.684-1.143)$ & $0.812(0.620-1.064)$ & $0.812(0.620-1.064)$ & \\
\hline No & 1065 & 1.0 (ref) & $1.817(1.111-2.973)$ & $1.732(1.054-2.847)$ & $3.467(1.833-6.558)$ & \\
\hline SOFA & & & & & & 0.955 \\
\hline$<5$ & 746 & 1.0 (ref) & $1.053(0.578-1.919)$ & $0.910(0.505-1.640)$ & $1.240(0.599-2.564)$ & \\
\hline$\geq 5$ & 1738 & 1.0 (ref) & $0.946(0.743-1.204)$ & $0.881(0.685-1.134)$ & $1.155(0.818-1.632)$ & \\
\hline Elixhauser score & & & & & & 0.450 \\
\hline$<13$ & 1154 & 1.0 (ref) & $0.665(0.458-0.964)$ & $0.623(0.422-0.921)$ & $0.916(0.537-1.561)$ & \\
\hline$\geq 13$ & 1330 & 1.0 (ref) & $1.150(0.871-1.518)$ & $1.066(0.800-1.420)$ & $1.406(0.963-2.051)$ & \\
\hline PT (second) & & & & & & 0.007 \\
\hline$<14.9$ & 1213 & 1.0 (ref) & $0.909(0.604-1.366)$ & $0.943(0.637-1.397)$ & $1.619(0.995-2.635)$ & \\
\hline$\geq 14.9$ & 1271 & 1.0 (ref) & $0.992(0.759-1.298)$ & $0.826(0.642-1.157)$ & $0.964(0.637-1.460)$ & \\
\hline PTT (second) & & & & & & 0.535 \\
\hline$<32$ & 1240 & 1.0 (ref) & $1.073(0.742-1.550)$ & $0.965(0.669-1.391)$ & $1.374(0.866-2.178)$ & \\
\hline$\geq 32$ & 1244 & 1.0 (ref) & $0.883(0.665-1.173)$ & $0.813(0.600-1.101)$ & $1.006(0.662-1.528)$ & \\
\hline $\mathrm{SpO}_{2}(\%)$ & & & & & & 0.528 \\
\hline$<97$ & 1212 & 1.0 (ref) & $0.894(0.658-1.214)$ & $0.742(0.532-1.034)$ & $1.231(0.788-1.924)$ & \\
\hline$\geq 97$ & 1272 & 1.0 (ref) & $0.976(0.702-1.357)$ & $0.977(0.704-1.355)$ & $1.043(0.680-1.600)$ & \\
\hline Temperature $\left({ }^{\circ} \mathrm{C}\right)$ & & & & & & 0.118 \\
\hline$<36.7$ & 1189 & 1.0 (ref) & $1.441(1.057-1.964)$ & $1.087(0.791-1.495)$ & $1.612(1.070-2.428)$ & \\
\hline$\geq 36.7$ & 1295 & 1.0 (ref) & $0.657(0.474-0.910)$ & $0.764(0.546-1.069)$ & $0.879(0.552-1.402)$ & \\
\hline Heart rate (beats/minute) & & & & & & 0.291 \\
\hline$<91.4$ & 1242 & 1.0 (ref) & $1.008(0.723-1.407)$ & $0.777(0.547-1.104)$ & $1.335(0.849-2.101)$ & \\
\hline$\geq 91.4$ & 1242 & 1.0 (ref) & $0.904(0.671-1.220)$ & $0.978(0.722-1.324)$ & $0.985(0.651-1.489)$ & \\
\hline MBP (mmHg) & & & & & & 0.037 \\
\hline$<70.1$ & 1234 & 1.0 (ref) & $1.125(0.837-1.512)$ & $0.854(0.622-1.172)$ & $1.422(0.932-2.171)$ & \\
\hline$\geq 70.1$ & 1250 & 1.0 (ref) & $0.816(0.579-1.151)$ & $0.958(0.684-1.341)$ & $0.928(0.587-1.466)$ & \\
\hline Respiratory rate (beats/minute) & & & & & & 0.428 \\
\hline$<21.4$ & 1336 & 1.0 (ref) & $0.916(0.667-1.257)$ & $0.832(0.598-1.159)$ & $1.482(0.966-2.274)$ & \\
\hline$\geq 21.4$ & 1148 & 1.0 (ref) & $0.989(0.722-1.355)$ & $0.825(0.595-1.145)$ & $0.891(0.562-1.411)$ & \\
\hline
\end{tabular}


TABle 3: Continued.

\begin{tabular}{|c|c|c|c|c|c|c|}
\hline \multirow[b]{2}{*}{ Characteristics } & \multirow[b]{2}{*}{ No. of patients } & \multicolumn{4}{|c|}{ BCR } & \multirow[b]{2}{*}{$\begin{array}{c}P \text { for } \\
\text { interaction }\end{array}$} \\
\hline & & $\begin{array}{c}<14.4 \\
\operatorname{HR}(95 \% \mathrm{CI})\end{array}$ & $\begin{array}{l}\geq 14.4,<20.0 \\
\operatorname{HR}(95 \% \mathrm{CI})\end{array}$ & $\begin{array}{c}\geq 20.0,<27.3 \\
\operatorname{HR}(95 \% \mathrm{CI})\end{array}$ & $\begin{aligned} & \geq 27.3 \\
\operatorname{HR} & (95 \% \mathrm{CI})\end{aligned}$ & \\
\hline Glucose (mg/dL) & & & & & & 0.624 \\
\hline 133.9 & 1242 & 1.0 (ref) & $0.971(0.710-1.327)$ & $1.078(0.781-1.488)$ & $1.497(0.982-2.281)$ & \\
\hline$\geq 133.9$ & 1242 & 1.0 (ref) & $0.867(0.626-1.199)$ & $0.686(0.492-0.957)$ & $0.808(0.514-1.268)$ & \\
\hline Albumin (g/dL) & & & & & & 0.451 \\
\hline$<2.7$ & 1194 & 1.0 (ref) & $1.171(0.860-1.595)$ & $1.083(0.781-1.500)$ & $1.538(1.004-2.355)$ & \\
\hline$\geq 2.7$ & 1290 & 1.0 (ref) & $0.826(0.594-1.148)$ & $0.751(0.542-1.041)$ & $1.008(0.659-1.541)$ & \\
\hline Bilirubin (mg/dL) & & & & & & 0.555 \\
\hline$<0.7$ & 1229 & 1.0 (ref) & $0.965(0.676-1.378)$ & $0.866(0.601-1.246)$ & $1.173(0.734-1.874)$ & \\
\hline$\geq 0.7$ & 1255 & 1.0 (ref) & $0.935(0.702-1.245)$ & $0.848(0.625-1.151)$ & $1.031(0.679-1.564)$ & \\
\hline Bicarbonate (mg/dL) & & & & & & 0.312 \\
\hline$<22$ & 1072 & 1.0 (ref) & $0.965(0.699-1.332)$ & $1.012(0.712-1.438)$ & $1.032(0.615-1.731)$ & \\
\hline$\geq 22$ & 1412 & 1.0 (ref) & $0.937(0.612-1.288)$ & $0.811(0.593-1.109)$ & $1.256(0.856-1.841)$ & \\
\hline Calcium (mmol/L) & & & & & & 0.981 \\
\hline$<8.1$ & 1172 & 1.0 (ref) & $0.971(0.700-1.346)$ & $0.891(0.618-1.285)$ & $1.197(0.717-1.997)$ & \\
\hline$\geq 8.1$ & 1312 & 1.0 (ref) & $0.899(0.663-1.217)$ & $0.826(0.611-1.117)$ & $1.116(0.764-1.630)$ & \\
\hline Potassium (mmol/L) & & & & & & 0.231 \\
\hline$<4.2$ & 1107 & 1.0 (ref) & $0.860(0.602-1.228)$ & $0.888(0.614-1.285)$ & $1.280(0.759-2.160)$ & \\
\hline$\geq 4.2$ & 1377 & 1.0 (ref) & $1.053(0.789-1.406)$ & $0.855(0.635-1.151)$ & $1.097(0.753-1.600)$ & \\
\hline Sodium (mmol/L) & & & & & & 0.098 \\
\hline$<13.8$ & 1222 & 1.0 (ref) & $0.877(0.641-1.200)$ & $0.765(0.555-1.055)$ & $1.013(0.652-1.573)$ & \\
\hline$\geq 13.8$ & 1262 & 1.0 (ref) & $1.016(0.737-1.402)$ & $0.950(0.681-1.325)$ & $1.306(0.848-2.011)$ & \\
\hline Hematocrit (\%) & & & & & & 0.329 \\
\hline$<33.3$ & 1234 & 1.0 (ref) & $0.935(0.679-1.285)$ & $0.984(0.712-1.360)$ & $1.337(0.884-2.023)$ & \\
\hline$\geq 33.3$ & 1250 & 1.0 (ref) & $0.933(0.681-1.277)$ & $0.769(0.550-1.074)$ & $0.928(0.592-1.455)$ & \\
\hline Anion gap & & & & & & 0.268 \\
\hline$<15$ & 1001 & 1.0 (ref) & $0.935(0.649-1.349)$ & $1.234(0.856-1.777)$ & $1.700(1.052-2.748)$ & \\
\hline$\geq 15$ & 1483 & 1.0 (ref) & $0.981(0.734-1.311)$ & $0.797(0.588-1.080)$ & $1.023(0.690-1.515)$ & \\
\hline Lymphocytes (\%) & & & & & & 0.712 \\
\hline$<7.1$ & 1242 & 1.0 (ref) & $0.837(0.607-1.154)$ & $0.881(0.635-1.222)$ & $1.095(0.709-1.693)$ & \\
\hline$\geq 7.1$ & 1242 & 1.0 (ref) & $1.000(0.730-1.370)$ & $0.855(0.613-1.193)$ & $1.171(0.770-1.781)$ & \\
\hline Neutrophils (\%) & & & & & & 0.308 \\
\hline$<81.9$ & 1219 & 1.0 (ref) & $0.957(0.684-1.340)$ & $0.902(0.641-1.270)$ & $1.357(0.874-2.107)$ & \\
\hline$\geq 81.9$ & 1265 & 1.0 (ref) & $0.939(0.697-1.265)$ & $0.914(0.666-1.254)$ & $1.113(0.719-1.723)$ & \\
\hline Hours of vasopressor & & & & & & 0.013 \\
\hline$<34$ & 1223 & 1.0 (ref) & $0.989(0.693-1.413)$ & $0.739(0.506-1.081)$ & $1.268(0.760-2.117)$ & \\
\hline$\geq 34$ & 1261 & 1.0 (ref) & $1.057(0.872-1.554)$ & $1.164(0.872-1.554)$ & $1.306(0.894-1.910)$ & \\
\hline Platelet $\left(10^{9} / \mathrm{L}\right)$ & & & & & & 0.008 \\
\hline$<214$ & 1241 & 1.0 (ref) & $0.782(0.567-1.079)$ & $0.824(0.595-1.142)$ & $1.312(0.853-2.017)$ & \\
\hline$\geq 214$ & 1243 & 1.0 (ref) & $1.062(0.774-1.457)$ & $0.888(0.641-1.233)$ & $0.962(0.617-1.501)$ & \\
\hline Hemoglobin (g/dL) & & & & & & 0.537 \\
\hline$<10.8$ & 1204 & 1.0 (ref) & $0.665(0.462-0.958)$ & $0.638(0.437-0.931)$ & $0.931(0.555-1.560)$ & \\
\hline$\geq 10.8$ & 1280 & 1.0 (ref) & $1.174(0.886-1.556)$ & $1.014(0.776-1.396)$ & $1.369(0.932-2.012)$ & \\
\hline Lactate $(\mathrm{mmol} / \mathrm{L})$ & & & & & & 0.499 \\
\hline$<1.3$ & 409 & 1.0 (ref) & $0.913(0.510-1.635)$ & $0.725(0.403-1.303)$ & $0.766(0.394-1.486)$ & \\
\hline$\geq 1.3$ & 2075 & 1.0 (ref) & $1.042(0.818-1.327)$ & $0.942(0.742-1.195)$ & $1.238(0.968-1.583)$ & \\
\hline
\end{tabular}


TABLE 3: Continued.

\begin{tabular}{|c|c|c|c|c|c|c|}
\hline \multirow[b]{2}{*}{ Characteristics } & \multirow[b]{2}{*}{ No. of patients } & \multicolumn{4}{|c|}{ BCR } & \multirow[b]{2}{*}{$\begin{array}{c}P \text { for } \\
\text { interaction }\end{array}$} \\
\hline & & $\begin{array}{c}<14.4 \\
\operatorname{HR}(95 \% \mathrm{CI})\end{array}$ & $\begin{array}{l}\geq 14.4,<20.0 \\
\operatorname{HR}(95 \% \text { CI })\end{array}$ & $\begin{array}{c}\geq 20.0,<27.3 \\
\text { HR }(95 \% \text { CI })\end{array}$ & $\begin{array}{c}\geq 27.3 \\
\operatorname{HR}(95 \% \mathrm{CI})\end{array}$ & \\
\hline INR & & & & & & 0.110 \\
\hline$<1.2$ & 898 & 1.0 (ref) & $0.782(0.529-1.157)$ & $0.796(0.533-1.189)$ & $1.108(0.667-1.841)$ & \\
\hline$\geq 1.2$ & 1586 & 1.0 (ref) & $1.052(0.802-1.379)$ & $0.874(0.661-1.157)$ & $1.120(0.768-1.634)$ & \\
\hline RDW & & & & & & 0.552 \\
\hline$<15.4$ & 1206 & 1.0 (ref) & $0.896(0.657-1.220)$ & $0.735(0.529-1.022)$ & $0.741(0.472-1.162)$ & \\
\hline$\geq 15.4$ & 1278 & 1.0 (ref) & $1.014(0.729-1.409)$ & $1.028(0.735-1.438)$ & $1.678(1.089-2.585)$ & \\
\hline WBC $\left(10^{9} / \mathrm{L}\right)$ & & & & & & 0.091 \\
\hline$<11.9$ & 1200 & 1.0 (ref) & $0.825(0.594-1.145)$ & $0.802(0.570-1.128)$ & $1.116(0.720-1.730)$ & \\
\hline$\geq 11.9$ & 1284 & 1.0 (ref) & $1.149(0.850-1.553)$ & $0.917(0.673-1.248)$ & $1.245(0.818-1.894)$ & \\
\hline Chronic pulmonary & & & & & & 0.906 \\
\hline Yes & 1889 & 1.0 (ref) & $0.954(0.585-1.554)$ & $0.963(0.580-1.598)$ & $1.283(0.674-2.442)$ & \\
\hline No & 595 & 1.0 (ref) & $0.922(0.717-1.185)$ & $0.840(0.647-1.090)$ & $1.084(0.767-1.531)$ & \\
\hline Cardiac arrhythmias & & & & & & 0.095 \\
\hline Yes & 1066 & 1.0 (ref) & $0.735(0.520-1.038)$ & $0.754(0.529-1.076)$ & $1.251(0.789-1.983)$ & \\
\hline No & 1418 & 1.0 (ref) & $1.176(0.879-1.573)$ & $0.988(0.731-1.335)$ & $1.162(0.776-1.739)$ & \\
\hline Coagulopathy & & & & & & 0.628 \\
\hline Yes & 1710 & 1.0 (ref) & $0.783(0.521-1.177)$ & $0.805(0.534-1.213)$ & $1.109(0.639-1.922)$ & \\
\hline No & 774 & 1.0 (ref) & $1.098(0.839-1.438)$ & $0.971(0.733-1.286)$ & $1.300(0.892-1.894)$ & \\
\hline Congestive heart failure & & & & & & 0.352 \\
\hline Yes & 951 & 1.0 (ref) & $0.791(0.541-1.156)$ & $0.876(0.596-1.287)$ & $1.261(0.739-2.154)$ & \\
\hline No & 1533 & 1.0 (ref) & $0.968(0.735-1.276)$ & $0.856(0.643-1.141)$ & $1.069(0.744-1.538)$ & \\
\hline Diabetes & & & & & & 0.748 \\
\hline Yes & 601 & 1.0 (ref) & $0.845(0.487-1.474)$ & $1.243(0.726-2.127)$ & $1.368(0.686-2.727)$ & \\
\hline No & 1883 & 1.0 (ref) & $0.987(0.773-1.260)$ & $0.862(0.667-1.113)$ & $1.100(0.781-1.549)$ & \\
\hline Fluid electrolyte & & & & & & 0.621 \\
\hline Yes & 1034 & 1.0 (ref) & $0.846(0.628-1.147)$ & $0.785(0.578-1.066)$ & $1.006(0.672-1.507)$ & \\
\hline No & 1450 & 1.0 (ref) & $1.142(0.820-1.591)$ & $1.060(0.750-1.496)$ & $1.462(0.925-2.312)$ & \\
\hline Hypertension & & & & & & 0.812 \\
\hline Yes & 1313 & 1.0 (ref) & $1.085(0.795-1.481)$ & $1.017(0.737-1.404)$ & $1.528(0.995-2.348)$ & \\
\hline No & 1171 & 1.0 (ref) & $0.922(0.666-1.275)$ & $0.904(0.644-1.268)$ & $1.038(0.660-1.632)$ & \\
\hline Liver disease & & & & & & 0.792 \\
\hline Yes & 542 & 1.0 (ref) & $0.924(0.582-1.468)$ & $0.999(0.619-1.611)$ & $1.093(0.596-2.006)$ & \\
\hline No & 1942 & 1.0 (ref) & $0.992(0.766-1.284)$ & $0.891(0.682-1.164)$ & $1.239(0.862-1.783)$ & \\
\hline Renal failure & & & & & & 0.299 \\
\hline Yes & 616 & 1.0 (ref) & $0.906(0.624-1.315)$ & $0.785(0.521-1.182)$ & $1.049(0.599-1.835)$ & \\
\hline No & 1868 & 1.0 (ref) & $0.963(0.727-1.275)$ & $1.036(0.781-1.374)$ & $1.402(0.967-2.034)$ & \\
\hline
\end{tabular}

BCR: blood urea nitrogen/creatinine ratio; RRT: renal replacement therapy; CHF: congestive heart failure; RDW: red blood cell distribution width; INR: international normal ratio; WBC: white blood cell count; SOFA: Sequential Organ Failure Assessment score.

suggesting that it was a risk factor and it was statistically significant. Clinicians should therefore note changes in renal function and BCR in septic shock patients in order to improve their prognosis.

The strengths of this study include it being the first time that the relationship between BCR and all-cause mortality has been investigated in septic shock patients based on a large and diverse population from a public database (the MIMICIII database), which increases the significance of our research results. In addition, after adjusting for several confounding factors, multiple Cox regression analyses were performed and the relationship between BCR and all-cause mortality was still observed, indicating the good stability of our results. Since BCR is the basic index of clinical blood routine, the parameters are simple to collect, and our research results can be used to support other death indexes and improve prognosis prediction accuracy for septic shock patients [35].

This study also had some limitations. Firstly, this study used data from a publicly accessible single-center database, which questions of the generalizability of our conclusions, 


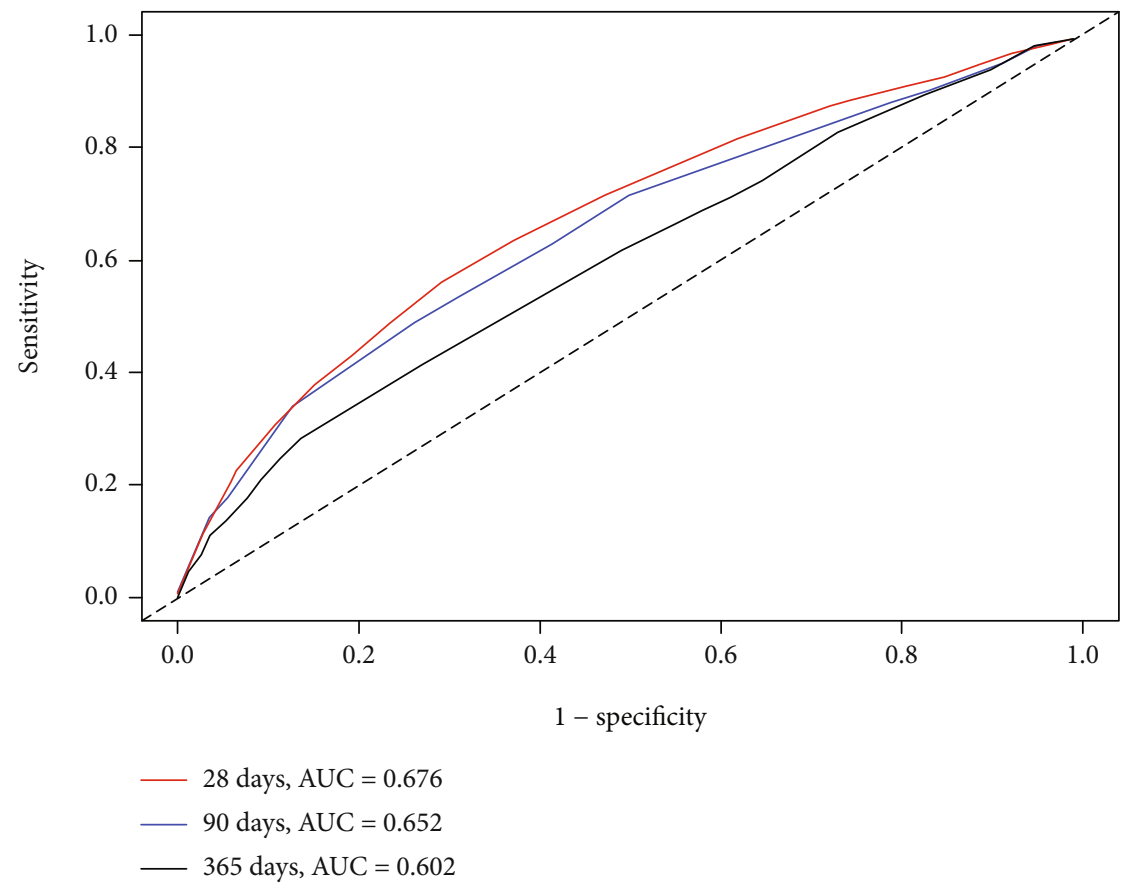

(a)

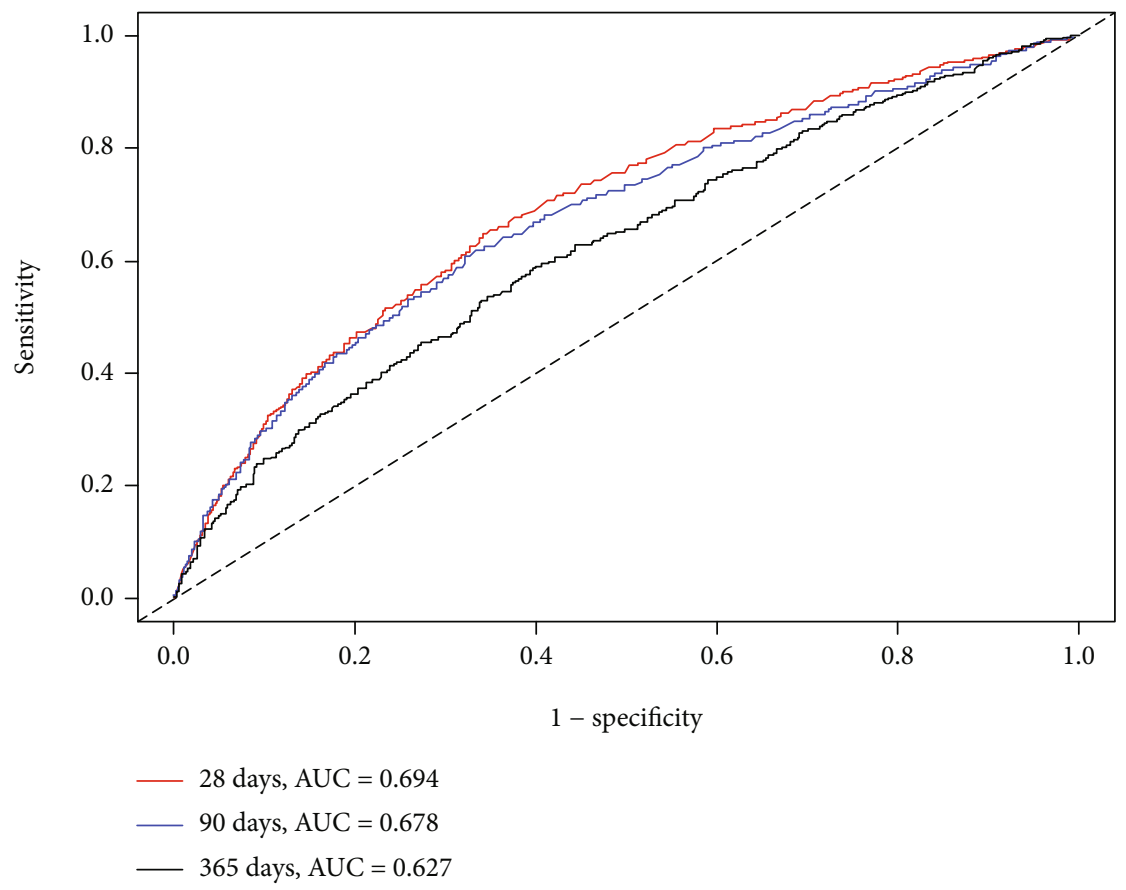

(b)

Figure 4: Continued. 


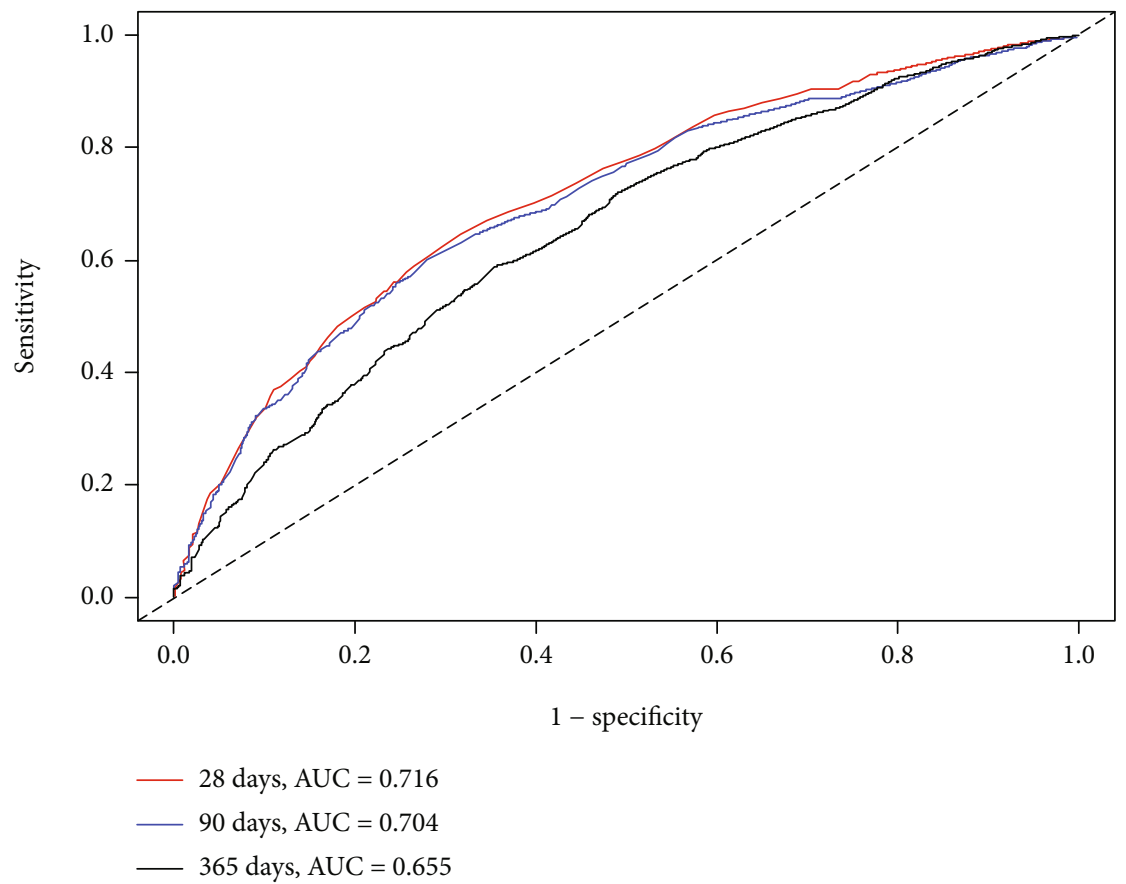

(c)

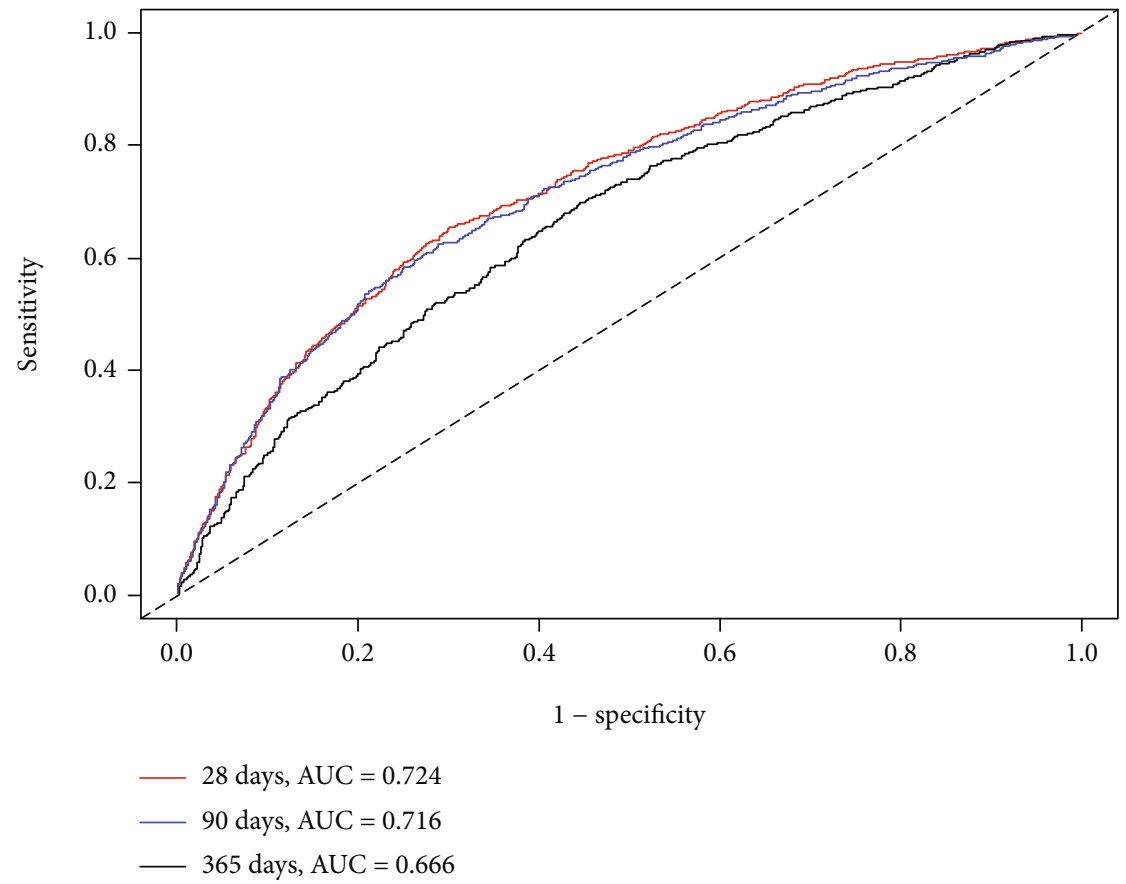

(d)

FIGURE 4: ROC curves for the prediction of mortality in critically ill patients with septic shock. $(\mathrm{a}, \mathrm{b})$ The ability of SOFA scores and BCR plus SOFA scores to predict 28-, 90-, and 365-day mortality. (c, d) The ability of APSIII scores and BCR plus APSIII scores to predict 28-, 90-, and 365-day mortality.

as well as confounding variables caused by missing data. However, this database has been utilized by many researchers globally, with the published articles improving the data quality, potentially improving the generalization of our findings. Secondly, BUN and Cr were measured only when the patient entered the ICU, without laboratory follow-up data. The measurement data may be classified incorrectly, which may affect the summary results. Thirdly, excluding patients who have not measured BUN and $\mathrm{Cr}$ values may cause sample selection bias. Finally, the database is relatively old, with patient information available between 2001 and 2012. Some information on septic shock diseases has changed recently, which may also affect the generalizability of our research results. 


\section{Conclusion}

Our research indicates that there is a nonlinear (M-shaped) relationship between BCR and all-cause mortality. Higher quartile BCR values will increase the 28-, 90-, and 365-day all-cause mortality rates of septic shock patients and can better guide the risk stratification of critically ill patients in clinical practice. The present findings need to be validated through further large-scale prospective studies and longer follow-ups.

\section{Abbreviations}

BCR: Blood urea nitrogen/creatinine ratio

ROC: Receiver operator characteristic curves

SOFA: Sequential Organ Failure Assessment score

APSIII: Acute Physiology Score III

BUN: Blood urea nitrogen

Cr: Creatinine

CHF: Congestive heart failure

PT: $\quad$ Prothrombin time

PTT: Partial thrombin time

RDW: Red blood cell distribution width

INR: International normal ratio

WBC: White blood cell count

MBP: Mean blood pressure

RRT: Renal replacement therapy

BMI: $\quad$ Body mass index

HRs: Hazard ratios

CIs: Confidence intervals

ICU: Intensive care unit

LOS: Length of stay

AUCs: Areas under the ROC curves.

\section{Data Availability}

The datasets used and/or analyzed during the present study were availed by the corresponding author on reasonable request.

\section{Disclosure}

The funder of the project was involved in study design, collection, data analysis, writing of the report, and publication.

\section{Conflicts of Interest}

The authors declare that they have no competing interests.

\section{Authors' Contributions}

Didi Han and Luming Zhang contributed equally to this study and should be considered co-first author.

\section{Acknowledgments}

The study was supported by (1) the National Social Science Foundation of China (No. 16BGL 183), (2) the National Natural Science Foundation of China (Nos. 82072232 and 81871585), (3) the Natural Science Foundation of Guang- dong Province (No. 2018A030313058), and (4) the Technology and Innovation Commission of Guangzhou Science, China (No. 201804010308).

\section{References}

[1] M. Singer, C. S. Deutschman, C. W. Seymour et al., "The third international consensus definitions for sepsis and septic shock (sepsis-3)," JAMA, vol. 315, no. 8, pp. 801-810, 2016.

[2] F. B. Mayr, S. Yende, and D. C. Angus, "Epidemiology of severe sepsis," Virulence, vol. 5, no. 1, pp. 4-11, 2014.

[3] D. F. Gaieski, J. M. Edwards, M. J. Kallan, and B. G. Carr, "Benchmarking the incidence and mortality of severe sepsis in the United States," Critical Care Medicine, vol. 41, no. 5, pp. 1167-1174, 2013.

[4] G. S. Martin, D. M. Mannino, S. Eaton, and M. Moss, “The epidemiology of sepsis in the United States from 1979 through 2000," The New England Journal of Medicine, vol. 348, no. 16, pp. 1546-1554, 2003.

[5] K. M. Kaukonen, M. Bailey, S. Suzuki, D. Pilcher, and R. Bellomo, "Mortality related to severe sepsis and septic shock among critically ill patients in Australia and New Zealand, 2000-2012," JAMA, vol. 311, no. 13, pp. 1308-1316, 2014.

[6] D. C. Angus, W. T. Linde-Zwirble, J. Lidicker, G. Clermont, J. Carcillo, and M. R. Pinsky, "Epidemiology of severe sepsis in the United States: analysis of incidence, outcome, and associated costs of care," Critical Care Medicine, vol. 29, no. 7, pp. 1303-1310, 2001.

[7] G. Kumar, N. Kumar, A. Taneja et al., "Nationwide trends of severe sepsis in the 21st century (2000-2007)," Chest, vol. 140, no. 5, pp. 1223-1231, 2011.

[8] K. Thompson, B. Venkatesh, and S. Finfer, "Sepsis and septic shock: current approaches to management," Internal Medicine Journal, vol. 49, no. 2, pp. 160-170, 2019.

[9] A. E. Jones, S. Trzeciak, and J. A. Kline, "The Sequential Organ Failure Assessment score for predicting outcome in patients with severe sepsis and evidence of hypoperfusion at the time of emergency department presentation," Critical Care Medicine, vol. 37, no. 5, pp. 1649-1654, 2009.

[10] M. T. Gilani, M. Razavi, and A. M. Azad, "A comparison of Simplified Acute Physiology Score II, Acute Physiology and Chronic Health Evaluation II and Acute Physiology and Chronic Health Evaluation III scoring system in predicting mortality and length of stay at surgical intensive care unit," Nigerian Medical Journal, vol. 55, no. 2, pp. 144-147, 2014.

[11] J. Núñez, G. Miñana, E. Santas, and V. Bertomeu-González, "Cardiorenal syndrome in acute heart failure: revisiting paradigms," Rev Esp Cardiol (Engl Ed), vol. 68, no. 5, pp. 426435, 2015.

[12] Y. Takaya, F. Yoshihara, H. Yokoyama et al., "Risk stratification of acute kidney injury using the blood urea nitrogen/creatinine ratio in patients with acute decompensated heart failure," Circulation Journal, vol. 79, no. 7, pp. 1520-1525, 2015.

[13] J. W. Schrock, M. Glasenapp, and K. Drogell, "Elevated blood urea nitrogen/creatinine ratio is associated with poor outcome in patients with ischemic stroke," Clinical Neurology and Neurosurgery, vol. 114, no. 7, pp. 881-884, 2012.

[14] S. Li and H. Chen, "Correlation between blood urea nitrogen/creatinine ratio and urinary specific gravity and prognosis of 
venous thrombolysis in acute cerebral infarction," PLA Medical Journal, vol. 28, no. 3, pp. 22-25, 2016.

[15] S. Uchino, R. Bellomo, and D. Goldsmith, "The meaning of the blood urea nitrogen/creatinine ratio in acute kidney injury," Clinical Kidney Journal, vol. 5, no. 2, pp. 187-191, 2012.

[16] A. E. Johnson, T. J. Pollard, L. Shen et al., "MIMIC-III, a freely accessible critical care database," Sci Data, vol. 3, no. 1, p. 160035, 2016.

[17] Y. Gong, D. Li, B. Cheng, B. Ying, and B. Wang, "Increased neutrophil percentage-to-albumin ratio is associated with allcause mortality in patients with severe sepsis or septic shock," Epidemiology and Infection, vol. 148, article e87, 2020.

[18] W. Ye, X. Chen, Y. Huang et al., "The association between neutrophil-to-lymphocyte count ratio and mortality in septic patients: a retrospective analysis of the MIMIC-III database," Journal of Thoracic Disease, vol. 12, no. 5, pp. 1843-1855, 2020.

[19] Z. Zhang, "Univariate description and bivariate statistical inference: the first step delving into data," Ann Transl Med, vol. 4, no. 5, p. 91, 2016.

[20] B. Wang, G. Aihemaiti, B. Cheng, and X. Li, "Red blood cell distribution width is associated with all-cause mortality in critically ill patients with cardiogenic shock," Medical Science Monitor, vol. 25, pp. 7005-7015, 2019.

[21] Y. Peng, J. Wang, H. Xiang et al., "Prognostic value of neutrophil-lymphocyte ratio in cardiogenic shock: a cohort study," Medical Science Monitor, vol. 26, article e922167, 2020.

[22] Z. Zhang, "Multiple imputation with multivariate imputation by chained equation (MICE) package," Ann Transl Med, vol. 4, no. 2, p. 30, 2016.

[23] M. Cecconi, L. Evans, M. Levy, and A. Rhodes, "Sepsis and septic shock," Lancet, vol. 392, no. 10141, pp. 75-87, 2018.

[24] C. Rhee, R. Dantes, L. Epstein et al., "Incidence and trends of sepsis in US hospitals using clinical vs claims data, 20092014," JAMA, vol. 318, no. 13, pp. 1241-1249, 2017.

[25] G. C. Fonarow, Adams KF Jr, W. T. Abraham, C. W. Yancy, W. J. Boscardin, and ADHERE Scientific Advisory Committee, Study Group, and Investigators, "Risk stratification for inhospital mortality in acutely decompensated heart failure: classification and regression tree analysis," JAMA, vol. 293, no. 5, pp. 572-580, 2005.

[26] A. J. Hartz, E. M. Kuhn, K. L. Kayser, and W. D. Johnson, "BUN as a risk factor for mortality after coronary artery bypass grafting," The Annals of Thoracic Surgery, vol. 60, no. 2, pp. 398-404, 1995.

[27] B. U. Wu, O. J. Bakker, G. I. Papachristou et al., "Blood urea nitrogen in the early assessment of acute pancreatitis: an international validation study," Archives of Internal Medicine, vol. 171, no. 7, pp. 669-676, 2011.

[28] M. J. Fine, T. E. Auble, D. M. Yealy et al., "A prediction rule to identify low-risk patients with community-acquired pneumonia," The New England Journal of Medicine, vol. 336, no. 4, pp. 243-250, 1997.

[29] A. Bacigalupo, R. Oneto, B. Bruno et al., "Early predictors of transplant-related mortality (TRM) after allogeneic bone marrow transplants (BMT): blood urea nitrogen (BUN) and bilirubin," Bone Marrow Transplantation, vol. 24, no. 6, pp. 653659, 1999.

[30] J. Han, G. Yue, L. Zheng, X. Mi, and L. Wang, "Clinical effect of CRRT on septic shock complicated with acute kidney injury," Chinese Modern Doctors, vol. 58, no. 19, p. 107, 2020.
[31] M. R. Cowie, M. Komajda, T. Murray-Thomas, J. Underwood, B. Ticho, and POSH Investigators, "Prevalence and impact of worsening renal function in patients hospitalized with decompensated heart failure: results of the prospective outcomes study in heart failure (POSH)," European Heart Journal, vol. 27, no. 10, pp. 1216-1222, 2006.

[32] J. M. Testani, J. Chen, B. D. McCauley, S. E. Kimmel, and R. P. Shannon, "Potential effects of aggressive decongestion during the treatment of decompensated heart failure on renal function and survival," Circulation, vol. 122, no. 3, pp. 265-272, 2010.

[33] N. Shiba, "Blood urea nitrogen/creatinine ratio in acute heart failure patients," Circulation Journal, vol. 79, no. 7, pp. 14461447, 2015.

[34] G. Parrinello, D. Torres, J. M. Testani et al., "Blood urea nitrogen to creatinine ratio is associated with congestion and mortality in heart failure patients with renal dysfunction," Internal and Emergency Medicine, vol. 10, no. 8, pp. 965-972, 2015.

[35] M. A. Brisco, M. R. Zile, J. M. ter Maaten et al., "The risk of death associated with proteinuria in heart failure is restricted to patients with an elevated blood urea nitrogen to creatinine ratio," International Journal of Cardiology, vol. 215, pp. 521526, 2016.

[36] P. R. Schloerb and M. Moncure, "Increased blood urea nitrogen/creatinine ratio with excess protein," Nutrition in Clinical Practice, vol. 19, no. 5, p. 539, 2004.

[37] L. C. Lin, J. T. Yang, H. H. Weng, C. T. Hsiao, S. L. Lai, and W. C. Fann, "Predictors of early clinical deterioration after acute ischemic stroke," The American Journal of Emergency Medicine, vol. 29, no. 6, pp. 577-581, 2011.

[38] L. C. Lin, W. C. Fann, M. H. Chou, H. W. Chen, Y. C. Su, and J. C. Chen, "Urine specific gravity as a predictor of early neurological deterioration in acute ischemic stroke," Medical Hypotheses, vol. 77, no. 1, pp. 11-14, 2011. 